\title{
Fragmentation and Constitutive Response of Tailored Mesostructured Aluminum Compacts
}

\author{
Andrew M. Marquez ${ }^{1}$, Christopher H. Braithwaite ${ }^{2}$, Timothy P. Weihs ${ }^{3}$, Nicholas \\ M. Krywopusk ${ }^{3}$, David J. Gibbins ${ }^{3}$, Kenneth S. Vecchio ${ }^{4}$, Marc A. Meyers ${ }^{1,4}$ \\ ${ }^{I}$ Materials Science and Engineering Program, University of California, San Diego, La \\ Jolla, California, 92093-0411, USA \\ ${ }^{2}$ SMF Group, Cavendish Laboratory, Cambridge, CB3 OHE, UK. \\ ${ }^{3}$ Johns Hopkins University, Baltimore, Maryland, 21218, USA. \\ ${ }^{4}$ Department of NanoEngineering, University of California, San Diego, La Jolla, \\ California, 92093, USA.
}

\begin{abstract}
The fragmentation and constitutive response of aluminum-based compacts was examined under dynamic conditions using mesostructured powder compacts in which the interfaces between the powders (sizes of 40,100, and $400 \mu \mathrm{m}$ ) were tailored during the swaging fabrication process. Fragmentation was induced in ring samples of this material through explosive loading and was examined through high speed photography, laser interferometry and soft capture of fragments. Fragment velocities of around $100 \mathrm{~m} / \mathrm{s}$ were recorded. The fragment mass distributions obtained correlated in general with the interfacial strength of the compacts as well as with powder size. Experimental results are compared with fragmentation theories to characterize the behavior of reactive powders based on the material's mesostructure by introducing the fracture toughness of the compacts. The mean fragment size is calculated using a modified form of Mott's theory and successfully compared with experimental results.
\end{abstract}

\section{INTRODUCTION}

The fragmentation of solids under dynamic loading is a subject of great importance, primarily in military applications, where the aim is to tailor the fragment size for high-explosive projectiles. Following the classic studies by Mott and coworkers [1-8] in the early 1940s, starting with the report by Mott and Linfoot [1] as part of the Allied war effort, a great deal of research has been conducted in this domain to predict and control fragmentation. The contribution by Grady [9] expands the original Mott ideas in a remarkable manner by changing the statistical representations of fragmentation.

There are a number of theories regarding fragmentation, but the two most relevant to this study are the classic Mott and Grady theories. Mott [1-8] based his theory on the earlier work of Lineau who modeled fragmentation as the random geometric fracture of an infinite onedimensional body. Mott and Linfoot [1] took the same random geometric fragmentation idea and applied it to a two-dimensional geometric model. They then formulated a fragment distribution law in the form:

$$
\mathrm{N}(\mathrm{m})=\exp \left[-\left(\frac{\mathrm{m}}{\mu}\right)^{\frac{1}{2}}\right]
$$


where $N(m)$ is the cumulative fragment distribution, $m$ is the mass of a fragment and the average mass $\mu$ is the distribution scale parameter, which is a measure of the statistical dispersion.

Later Grady and Kipp [10] suggested that if fragmentation can be represented by mechanismindependent statistical descriptions then fragment mass, as opposed to fragment size, is the more fitting random variable. They also suggested that the mass of the fragment is distributed over the fragment number based on a Poisson process, or binomial if the fragment number is small, similar to the earlier developments of Lineau. From this suggestion they proposed the following linear exponential distribution:

$$
\mathrm{N}(\mathrm{m})=\exp \left(-\frac{\mathrm{m}}{\mu}\right)
$$

An alternative explanation for the nature of mechanism-independent statistical description was developed by Davydova et al. [11] Based on statistical regularities in the fragmentation of cylindrical quartz specimens under dynamic loading it was determined that scaling invariance is the physical reason for the mechanism-independent statistical laws. The results of the experimental data processing in the study showed that the size distribution for fragment size is described by a power function.

In this paper, we report experimental results of explosive expanding ring tests of tailored mesostructured aluminum compacts. We analyze the constitutive response of each aluminum compact through quasi-static and dynamic mechanical tests in order to predict the fragment sizes with a modified Mott theory that utilizes the fracture toughness of the compacts. We observe with analysis of the results that the modified Mott theory we developed successfully predicts the fragment sizes for most of the compacts.

\section{EXPERIMENTAL PROCEDURES AND SAMPLE PROCESSING}

The primary motivation of the current research was to tailor the fragmentation response of aluminum by changing the interfacial cohesion between particles. Two variables were altered for this purpose. The first variable was the particle size; three different aluminum compacts were used: $\sim 40 \mathrm{~m}$ aluminum particles (Figure 1(a)), 100 $\mu \mathrm{m}$ aluminum particles (Figure 1(b)), and $\sim 400 \mu \mathrm{m}$ aluminum particles (Figure 1(c)). Figure 1 shows the morphologies of the different particle sizes through images taken by scanning electron microscopy conducted using a FEI XL30-SFEG SEM. The $\sim 40 \mu \mathrm{m}$ size Al powder had relatively homogeneous shapes and particle sizes, mainly being smooth and spherical. The $\sim 400 \mu \mathrm{m}$ size Al powder consisted of more complicated shapes and a substantial variety of particle sizes (from 350 to $500 \mu \mathrm{m}$ ), so steel sieves were used to narrow the distribution and center it around $400 \mu \mathrm{m}$. The $\sim 100 \mu \mathrm{m}$ size Al powder also had complex morphology but the particle size distribution $(100-125 \mu \mathrm{m})$ was more tightly defined and sieving was not required. The $\sim 40 \mu \mathrm{m}$ size $\mathrm{Al}$ powder has a greater tendency to agglomeration partly because of the large increases of surface area to volume ratio and that fact that the van der Waals attraction forces become gradually more relevant as the grain size is reduced [12]. As a result, the $40 \mu \mathrm{m}$ size Al particles have a spongy (or porous) arrangement. 
The other variable changed was the strength of the interface through a sample processing technique based on powder densification.

\section{A. Swaging}

Swaging, illustrated in Figure 2(a), is a standard forging process where a rapidly rotating die uniformly reduces the diameter of a tube or rod by cold working. Aluminum powders of approximate sizes 40,100, and $400 \mu \mathrm{m}$ were compacted into tubes of AISI 304 stainless steel in an Instron 5582, as depicted in Figure 2(b), and then were swaged to a smaller diameter using a Fenn 5F swager. Tight fitting $12.7 \mathrm{~mm}$ rods of Al 6061 were secured in the center of the tubes prior to the compaction of the powders and swaging. The rods were machined out later along with the stainless steel jackets to generate hollow cylinders with $30 \mathrm{~mm}$ OD and $22 \mathrm{~mm}$ ID that were cut into $4 \mathrm{~mm}$ thick rings, an example of which is shown in Figure 2(d). In the case of the $100 \mu \mathrm{m}$ powder, the center rod was also varied in size to $18.8 \mathrm{~mm}$ or removed to observe the effect of different degrees of compaction. As the compaction increases one expects more adhesion between the individual particles [13] because of the greater amount of plastic deformation. The presence of the core increases the amount of plastic deformation for a certain fraction of densification because the particles are not only brought together but there is also significant interparticle shear and breaking of surface oxides.

\section{B. Expanding ring technique}

The rings described in the previous section were used for explosively driven fragmentation tests conducted using the experimental set-up shown in Figure 3(a). This experimental setup provides high speed photography of the ring expansion, time resolved velocimetry of the radial expansion of the ring and soft capture of the ring fragments to allow for post fracture analysis [14]. The ring is loaded through the use of a column of explosives contained within a "transmitter" tube. A steel cylinder coated with approximately $20 \mathrm{~mm}$ of paraffin wax is placed around the specimen so that the fragments slow to a stop before impinging on the steel, eliminating the chance of secondary deformation. High speed photography is conducted parallel to the cylinder axis through the setup shown in Figure 3(b). The radial expansion velocity of the ring is measured by a PDV system [15] with the probe being a bare fiber placed approximately 3-5 $\mathrm{mm}$ from the ring.

\section{Mechanical testing}

Small cylindrical samples with dimensions of $4 \mathrm{~mm}$ (length) x $3 \mathrm{~mm}$ (diameter) were machined from the inside of the swaged aluminum rings, parallel to the ring axis. These samples were mechanically tested in a universal testing machine (Model Instron 3370) and split Hopkinson pressure bar. The samples were compressed quasi-statically with the Instron at strain rates of $10^{-2}, 10^{-3}$, and $10^{-4} \mathrm{~s}^{-1}$. For the dynamic testing a copper pulse-shaper with a high workhardening rate was utilized to create a long rise time and nearly square strain rate pulse [16]. Strain rates of $\sim 2.5 \times 10^{3} \mathrm{~s}^{-1}$ were attained through this technique. Vickers indentation 
experiments were conducted on the rings in order to characterize the microhardness of the different particle sizes.

\section{RESULTS AND DISCUSSION}

\section{A. Mechanical response}

The quasi-static compression test results (Figures 4a and b) revealed that the swaged $400 \mu \mathrm{m}$ aluminum samples have the highest yield stresses ( 127 MPa), followed by the swaged $40 \mu \mathrm{m}$ aluminum samples( 94 MPa), and then the swaged $100 \mu \mathrm{m}$ aluminum samples. ( 75 MPa with no core, $\sim 68 \mathrm{MPa}$ with $18.8 \mathrm{~mm}$ core and $\sim 56 \mathrm{MPa}$ with $12.7 \mathrm{~mm}$ core). The dynamic yield stresses, shown in Figure 4(c), varied from 75 to $150 \mathrm{MPa}$ and are moderately higher than the quasi-static values. The order of highest dynamic yield stresses was consistent with the quasistatic results. There is a slight incompatibility for the $100 \mu \mathrm{m}$ specimen with $12.7 \mathrm{~mm}$ core at the $10^{-3} \mathrm{~s}^{-1}$ strain rate. The quasi-static and dynamic yield stresses are plotted as a function of strain rate in Figure 4(d). From that plot the strain-rate sensitivity, m, a parameter that measures how much a material's flow stress and work-hardening rate may be affected by strain rate, of the aluminum compacts can be determined.

The strain-rate sensitivity is defined as $m=\partial \ln \sigma / \partial \ln \dot{\varepsilon}$. The low strain-rate sensitivity is consistent with pure aluminum, which has been investigated earlier [17]. The strain-rate sensitivity and microindentation Vickers hardness values (VHN) of the rings are shown in Table 1. $\mathrm{M}$ is not significantly affected by the processing parameters, whereas the hardness is, as expected.

TABLE I. Micro-hardness results for the different compacts.

\begin{tabular}{|l|l|l|l|l|c|}
\hline Compacts & $\begin{array}{l}40 \mu \mathrm{m} \mathrm{Al} \\
(12.7 \mathrm{~mm} \\
\text { core })\end{array}$ & $\begin{array}{l}100 \mu \mathrm{m} \mathrm{Al} \\
(\text { No core })\end{array}$ & $\begin{array}{l}100 \mu \mathrm{m} \mathrm{Al} \\
(12.7 \mathrm{~mm} \\
\text { core })\end{array}$ & $\begin{array}{l}100 \mu \mathrm{m} \mathrm{Al} \\
(18.8 \mathrm{~mm} \\
\text { core })\end{array}$ & $\begin{array}{l}400 \mu \mathrm{m} \mathrm{Al} \\
(18.8 \mathrm{~mm} \\
\text { core })\end{array}$ \\
\hline $\begin{array}{l}\text { Strain-rate } \\
\text { sensitivity }\end{array}$ & 0.0070 & 0.0065 & 0.0079 & 0.0081 & 0.0085 \\
\hline $\begin{array}{l}\text { Hardness } \\
(\mathrm{GPa})\end{array}$ & $0.43 \pm 0.03$ & $0.33 \pm 0.02$ & $0.28 \pm 0.09$ & $0.53 \pm 0.06$ & $0.68 \pm 0.09$ \\
\hline
\end{tabular}

\section{B. Fracture toughness determination}

In order to predict fragment sizes using the modified Mott equation developed in this study (Section III.C.3), fracture toughness values must be determined for the various conditions of swaged Al powder compacts. Experiments were conducted to obtain the fracture toughness values using the ASTM standard test method for linear-elastic plane-strain fracture toughness of metallic materials (ASTM E399) with some slight variations. Arc-shaped tension specimens (as seen in the high speed stills in Figure 5) were constructed from the swaged aluminum rings by 
sectioning them in half and cutting a starter notch in the center of the half-rings. However, instead of machining loading holes that could affect the behavior of the swaged materials, loading fixtures were constructed to allow for tensile testing without the necessity of holes in the specimens. The modification of the supports from the ones recommended in ASTM E399 is not thought to alter the effectiveness of the testing procedure significantly.

During the tensile tests a high speed camera was used to measure the displacement of the crack mouth instead of displacement gages. The crack mouth opening displacement (CMOD) was measured frame by frame and compared to the force-time record to obtain a force-CMOD record as shown in Figure 6. The conditional force is used to calculate the fracture toughness value by using the procedure detailed in ASTM E 399 and the following equation:

$$
K_{Q}=\frac{P_{Q}}{B \sqrt{W}}\left(3 \frac{X}{W}+1.9+1.1 \frac{a}{W}\right)\left[1+0.25\left(1-\frac{a}{W}\right)^{2}\left(1-\frac{r_{1}}{r_{2}}\right)\right] \cdot f\left(\frac{a}{W}\right)
$$

where: $f\left(\frac{a}{W}\right)=\frac{\sqrt{\frac{a}{W}}}{\left(1-\frac{a}{W}\right)^{3 / 2}}\left[3.74-6.30 \frac{a}{W}+6.32\left(\frac{a}{W}\right)^{2}-2.43\left(\frac{a}{W}\right)^{3}\right]$

$B$ is the specimen thickness, $X$ is the loading offset, $W$ is the width (depth) of the specimen, $a$ is the crack size and $r_{1} / r_{2}$ is the ratio of inner-to-outer radii [18]. The measured fracture toughness values of the compacts are presented later in Table 3 along with the predicted fragment sizes calculated from these values.

\section{Fragmentation}

As described previously, the fragmentation of the rings in the expanding ring experiments was captured with a high speed photography system set up parallel to the cylinder axis. The photographs are shown in Figures 7-11. The approximate number of fragments from each experiment is shown in Table 2. The mass of each fragment from the experiments was measured for a statistical analysis with the exception of the $100 \mu \mathrm{m}$ swaged Al powder ring with no core, which produced a large majority of fragments so small in mass they could not easily be statistically characterized.

TABLE II. Number of fragments from expanding ring tests of swaged Al compacts

\begin{tabular}{|l|l|l|l|l|l|}
\hline Compacts & $\begin{array}{l}40 \mu \mathrm{m} \mathrm{Al} \\
(12.7 \mathrm{~mm} \\
\text { core })\end{array}$ & $\begin{array}{l}100 \mu \mathrm{m} \mathrm{Al} \\
(\text { No core })\end{array}$ & $\begin{array}{l}100 \mu \mathrm{m} \mathrm{Al} \\
(12.7 \mathrm{~mm} \\
\text { core })\end{array}$ & $\begin{array}{l}100 \mu \mathrm{m} \mathrm{Al} \\
(18.8 \mathrm{~mm} \\
\text { core })\end{array}$ & $\begin{array}{l}400 \mu \mathrm{m} \mathrm{Al} \\
(18.8 \mathrm{~mm} \\
\text { core })\end{array}$ \\
\hline $\begin{array}{l}\text { Fragment } \\
\text { number }\end{array}$ & 8 & $\sim 1000$ & $\sim 700$ & $\sim 600$ & 25 \\
\hline
\end{tabular}

\section{C.1 Characterization of fracture}

Scanning electron microscopy was used to characterize the failure morphology in fragments of the rings. The distinction between the fragment mass distributions of the rings is consistent with the failure morphologies seen in Figures 12 and 13. The outer deformed fracture surfaces of the swaged 40 and $400 \mu \mathrm{m}$ aluminum fragments (Figures 12a and b) exhibit wavy and uneven 
surfaces that are typical of ductile deformation. The dimple morphology demonstrated on the edges of these fragments is characteristic of ductile failure as well. In contrast, the fragments of the swaged $100 \mu \mathrm{m}$ aluminum rings, shown in Figures 13(a-c), demonstrate features that are indicative of a brittle failure such as interfacial cracking. The dissimilarity in the fracture surfaces exemplifies how a brittle failure induces the production of more fragments.

\section{C.2 Fragment size distribution}

The fragment mass distribution from each expanding ring experiment with the exception of the $100 \mu \mathrm{m}$ swaged Al powder ring with no core was analyzed. There are multiple fragment mass distribution laws, but for this analysis the classic Mott and Grady distributions were used. Figure 14(a-d) illustrates the comparison of cumulative fragment mass distributions. It is difficult to establish a relationship when there are few fragments, such as in the case of the swaged 40 and $400 \mu \mathrm{m}$ aluminum fragments (Figures $14 \mathrm{a}$ and $\mathrm{b}$ ), but it is evident in the swaged $100 \mu \mathrm{m}$ aluminum distributions (Figures $14 \mathrm{c}$ and $\mathrm{d}$ ) that the Grady distribution provides a better description of the mass distribution of fragments generated in the expanding ring experiments.

\section{C.3 Prediction of mean fragment sizes}

Mott and Linfoot [1] proposed, in 1943, a simple theory for the prediction of mean fragment sizes based on an energy balance, akin to the Griffith [19] theory for crack propagation. Although many more complex analyses have been developed since then, the fundamental analysis by Mott will be used for our purpose as it is the most basic analysis to expand upon. The Mott equation will be presented here, with a slight modification. The basic derivation of the Mott-Linfoot equation is presented first. Figure 15 shows a schematic of a ring expanding and fragmenting; a segment of size $a$ just prior to fragmentation is shown in Figure 15(b). The radial velocity is $V_{l}$. Since the ring is expanding, the extremities also have a tangential velocity $V_{t}$. The arc has an angle $\alpha$ and therefore we have the following, after the arc has expanded to $r+d r$ :

$$
\begin{aligned}
& V_{l}=\frac{d r}{d t} \\
& V_{t}=\frac{d a}{2 d t}
\end{aligned}
$$

Thus:

$$
V_{t}=\frac{d a V_{l}}{2 d r}
$$

But:

$$
a=\alpha r \text { and } d a=\alpha d r
$$

Substituting Eqn. 7 into Eqn. 6:

$$
V_{t}=\frac{\alpha V_{r}}{2}
$$


These are the velocities of both the upper and lower edges of the segment of size $a$. The kinetic energy due to the expansion of the ring can be calculated per unit of length parallel to the axis of the disk. First consider an origin moving within the fragment. Then define an angle $\alpha$ that is marked in Figure 15. The velocity varies with increasing $\alpha$ as:

$$
V_{t}=\frac{\alpha V_{l}}{2}
$$

The mass per unit of length along the axis of a sliver defined by $d \alpha$ is expressed as:

$$
d m=\rho \operatorname{trd} \alpha
$$

Where $t$ is the thickness of the ring, $r d \alpha$ is the length of the sliver, and $\rho$ is the density of the material. Thus, the kinetic energy is:

$$
d E_{k}=\frac{1}{2} \rho \operatorname{tr} \frac{\alpha^{2} V_{l}^{2}}{4} d \alpha
$$

The total kinetic energy for the entire segment is obtained by integrating from $-\alpha / 2$ to $+\alpha / 2$ :

$$
E_{k}=\int_{-\alpha / 2}^{+\alpha / 2} d E_{k}=\int_{-\alpha / 2}^{+\alpha / 2} \frac{1}{2} \rho \operatorname{tr} \frac{\alpha^{2} V_{l}^{2}}{4} d \alpha=\frac{1}{24} \rho \operatorname{tr} V_{l}^{2} \alpha^{3}
$$

Mott [1] made the simple assumption that the kinetic energy was converted into the energy to generate two cracks at the extremities of the fragment. Since the number of cracks is equal to the number of fragments, only one crack has to be considered per fragment. Here we replace Mott and Linfoot's energy per unit area required to form a crack by the energy release rate, $G$, which expresses the same. For a thickness $t$ :

$$
\frac{1}{24} \rho \operatorname{tr} V_{l}^{2} \alpha^{3}=G t
$$

The fracture toughness, $K_{I c}$, is introduced through the simple relationship:

$$
G=\frac{K_{I c}^{2}}{E}
$$

where E is the Young's modulus. Thus, the fragment size can be obtained, by substituting Eqns. 7 and 14 into Eqn. 13:

$$
a=\left(\frac{24 r^{2} K_{I c}^{2}}{V_{l}^{2} \rho E}\right)^{1 / 3}
$$

The introduction of the strain energy (a potential energy term) into the Mott theory can be simply effected through the addition of:

$$
E_{p}=\left(\frac{1}{2} \sigma_{y} \varepsilon\right) a t
$$

By using Hooke's law, since the plastic energy is not recoverable:

$$
E_{p}=\frac{\sigma_{y}^{2}}{2 E} a t
$$


Adding Eqn. 17 to the first term of Eqn. 13 and Eqn. 14 to the second term we arrive at:

$$
a^{3}+\frac{24 r^{2} \sigma_{y}^{2}}{2 E \rho V_{l}^{2}} a-\frac{24 r^{2} K_{I c}^{2}}{E \rho V_{l}^{2}}=0
$$

Eqn. 18 shows that, for a fixed velocity, the fragment size is a function of both the strength and fracture toughness. The solution of this incomplete third order equation $a^{3}+p a+q=0$ by Cardano's method gives the following only real root:

$$
a=\left(-\frac{q}{2}+D^{1 / 2}\right)^{1 / 3}+\left(-\frac{q}{2}-D^{1 / 2}\right)^{1 / 3}
$$

Where $D=\left(\frac{p}{3}\right)^{3}+\left(\frac{q}{2}\right)^{2}$

We apply Eqn. 18 to aluminum rings, keeping in mind that the tailored microstructures introduced by compaction and swaging of the powders reduces the fracture toughness significantly from the original value of $60 \mathrm{MPam}^{1 / 2}$, which can be assumed for annealed 1100 aluminum. We take five different arbitrary values of $\mathrm{K}_{\mathrm{Ic}}$ to demonstrate its effect on the mean fragment size: $100,50,10,5$, and $1 \mathrm{MPam}^{1 / 2}$. For the calculations, the following values were used: $\mathrm{V}_{\mathrm{l}}=100$ and $500 \mathrm{~m} / \mathrm{s} ; \mathrm{E}=70 \mathrm{GPa} ; \rho=2.7 \times 10^{3} \mathrm{~kg} / \mathrm{m}^{3} ; \mathrm{r}=12 \times 10^{-3} \mathrm{~m}$.

One factor to consider is that, once the fragment size becomes smaller than $t$, the ring thickness, fragments tend to become equiaxed and the equations no longer apply. A conversion to fragment mass is in order at this point. One can set, to a first approximation, mass $=\rho a^{3}$. Figure 15(c) shows predictions of the modified Mott theory for fragment size as a function of fracture toughness. Thus once a fracture toughness value is attained it can be used with other experimentally determined values in Eqn. 18 to predict a mean fragment size. The calculated fracture toughness values and experimentally measured mean fragment sizes for each of the compacts are shown in Table 3.

The experimentally measured mean fragment sizes of the swaged aluminum are compared to the predicted values based on measured fracture toughness using the modified Mott theory (Eqn. 18) in Figure 16. The predicted response is given by the dot dashed, dashed, and dotted lines for yield stresses of 50,100, and $150 \mathrm{MPa}$, respectively; the experimentally measured fragment sizes are given by the solid line. The yield stress for each condition is marked in the plot. With the exception of the $\sim 40$ micron aluminum swaged with a $12.7 \mathrm{~mm}$ core $\left(\mathrm{K}_{\mathrm{Ic}}=\right.$ $\left.3.04 \mathrm{MPam}^{1 / 2} ; \sigma_{\mathrm{y}}=94 \mathrm{MPa}\right)$ the experimentally measured mean fragment sizes correlate reasonably well with the predictions, being higher than the predicted in all cases. This can be due to fractures that did not open completely and therefore leading to two or more fragments being counted as one. The aluminum with the lowest fracture toughness, the $\sim 100$ micron aluminum swaged with no core, could actually be closer to the predictions if not for the fact that the fragments were so small that they were compacted together during the explosion in the expanding ring experiment as shown in Figure 17. Therefore, the modified Mott theory could be used to predict fragment sizes for materials within ranges of yield stresses typical to that material. 
TABLE III. Measured fracture toughness values and predicted and measured mean fragment sizes for the different compacts.

\begin{tabular}{|l|c|c|c|c|c|}
\hline Compacts & $\begin{array}{l}40 \mu \mathrm{m} \mathrm{Al} \\
(12.7 \mathrm{~mm} \\
\text { core) }\end{array}$ & $\begin{array}{l}100 \mu \mathrm{m} \mathrm{Al} \\
\text { (No core) }\end{array}$ & $\begin{array}{l}100 \mu \mathrm{m} \mathrm{Al} \\
(12.7 \mathrm{~mm} \\
\text { core) }\end{array}$ & $\begin{array}{l}100 \mu \mathrm{m} \mathrm{Al} \\
(18.8 \mathrm{~mm} \\
\text { core) }\end{array}$ & $\begin{array}{l}400 \mu \mathrm{m} \mathrm{Al} \\
(18.8 \mathrm{~mm} \\
\text { core) }\end{array}$ \\
\hline $\begin{array}{l}\text { Fracture } \\
\text { toughness } \\
\text { value } \\
\left(\mathrm{MPa}^{*} \mathrm{~m}^{1 / 2}\right)\end{array}$ & 3.04 & 0.12 & 0.59 & 0.75 & 3.90 \\
\hline $\begin{array}{l}\text { Predicted } \\
\text { mean } \\
\text { fragment size } \\
(\mathrm{mm})\end{array}$ & 2.10 & 0.01 & 0.30 & 0.40 & 2.70 \\
\hline $\begin{array}{l}\text { Experimental } \\
\text { mean } \\
\text { fragment size } \\
(\mathrm{mm})\end{array}$ & 8.03 & 0.53 & 0.43 & 0.39 & 3.67 \\
\hline
\end{tabular}

\section{CONCLUSIONS}

Aluminum compacts of different particle sizes were processed through swaging. Quasi-static and dynamic compression tests were conducted to analyze the constitutive response of the compacts. Particle size and degree of compaction were determined to have a direct effect on constitutive response of the swaged aluminum. Fracture toughness values for the modified Mott equation were attained using the ASTM standard test method for linear-elastic plane-strain fracture toughness of metallic materials (ASTM E399) with some slight variations. Expanding ring tests were also conducted on the compacts to examine the fragmentation behavior of the compacts. Scanning electron microscopy was utilized to investigate the fracture response of the swaged Al rings, the swaged $400 \mu \mathrm{m}$ and $40 \mu \mathrm{m}$ particle Al rings demonstrated ductile fracture behavior while the swaged $100 \mu \mathrm{m}$ particle Al rings showed features indicative of a brittle material failure. The more ductile swaged $400 \mu \mathrm{m}$ and $40 \mu \mathrm{m}$ particle $\mathrm{Al}$ rings produced far fewer fragments than the more brittle swaged $100 \mu \mathrm{m}$ particle $\mathrm{Al}$ rings. A possible reason for the weaker compacts from 100 um particles is surface contamination of the powders which led to weaker interfaces. Fragmentation number statistics of the swaged aluminum tend to follow a Grady distribution more so than a Mott distribution. Fragment mean size predictions were attempted with a modified Mott equation similar to the Grady-Kipp theory. The experimentally measured mean fragment sizes were found to be close to the predictions of fragment size based on fracture toughness by the modified Mott theory in all but one of the conditions of swaged aluminum as observed in Figure 16. For this condition the particles were swaged most successfully producing a much higher fracture toughness than anticipated. 


\section{Acknowledgements}

The authors gratefully acknowledge financial support provided by ONR/MURI Grant No. N00014-07-1-0740 (Program Officer Dr. Clifford Bedford). We acknowledge Prof. V. F. Nesterenko for the use of the high speed camera. Discussions with Dr. S. Walley at Cavendish Laboratory are gratefully acknowledged.

\section{References}

N. F. Mott and E. H. Linfoot, Ministry of Supply, AC 3348, January, 1943.

2 N.F. Mott, Ministry of Supply, AC3642, March, 1943.

3 N.F. Mott, Ministry of Supply, AC4035, May, 1943.

4 N.F. Mott, Ministry of Supply, AC4613, August, 1943.

$5 \quad$ N.F. Mott, Ministry of Supply, AC6338, May, 1944.

6 N.F. Mott, J.H. Wilkinson, and T.H. Wise, Ministry of Supply, AC6338, December, 1944.

7 N. F. Mott, Proc. R. Soc. Lon. 300, 300 (1947).

$8 \quad$ N. F. Mott, Eng. 165, 16 (1948).

9 D. Grady, Fragmentation of Rings and Shells (Springer-Verlag, Berlin and Heidelberg, 2006), Chap. 2.

10 D.E. Grady and M.E. Kipp, J. Appl. Phys. 58, 1210 (1985).

11 M.M. Davydova, S.V. Uvarov, and O.B. Naimark, Phys. Meso. 17, 81 (2014).

12 R.Y. Yang, A.B. Yu, S.K. Choi, M.S. Coates, and H.K. Chan, Powder Tech. 184, 122 (2008).

13 J. D. Gibbins, A. K. Stover, N. M. Krywopusk, K. Woll, and T.P. Weihs, Comb. and Fla. $1(2015)$.

14 C. Braithwaite, B. Aydelotte, A. Collins, N. Thadhani, and D. Williamson, AIP Conf. Proc. 1426, 1049 (2012).

15 V. Nesterenko, P. Chiu, C. Braithwaite, A. Collins, D. Williamson, K. Olney, D. Benson, and F. McKenzie, AIP Conf. Proc. 1426, 533 (2012).

16 K. S. Vecchio and F.C. Jiang, Metall. Mater. Trans. A 38, 2655 (2007).

17 U.S. Lindholm, J. Mech. Phys. Sol. 12, 317 (1964).

18 J.A. Kapp, J.C. Newman, and J.H. Underwood, Jr., J. Test. Eval. 8, 314 (1980).

19 A.A. Griffith, Philos. Trans. R. Soc., A 221, 163 (1921).

20 D. Grady and D. A. Benson, Exptl. Mech. 23, 393 (1983).

21 G.R. Johnson and W.H. Cook, Eng. Fract. Mech. 21, 31 (1985).

22 D.E. Grady and M.L. Olsen, J. Imp. Eng. 29, 293 (2003).

23 E. Vitali, C.-T. Wei, D.J. Benson, and M.A. Meyers, Acta. Mat. 59, 5869 (2011).

24 E.B. Herbold, J.L. Jordan, and N.N. Thadhani, Acta. Mat. 59, 6717 (2011). 
25 R. Ames, in MRS Symposium Proceedings, edited by A. Gash, N. Thadhani, W.Wilson, R. Armstrong, and Z. Munir (Pittsburgh, PA, 2006), Vol. 896.

26 C.T. Wei, E. Vitali, F. Jiang, S.W. Du, D.J. Benson, K.S. Vecchio, N.N. Thadhani, and M.A. Meyers, Acta. Mat. 60, 1418 (2012).

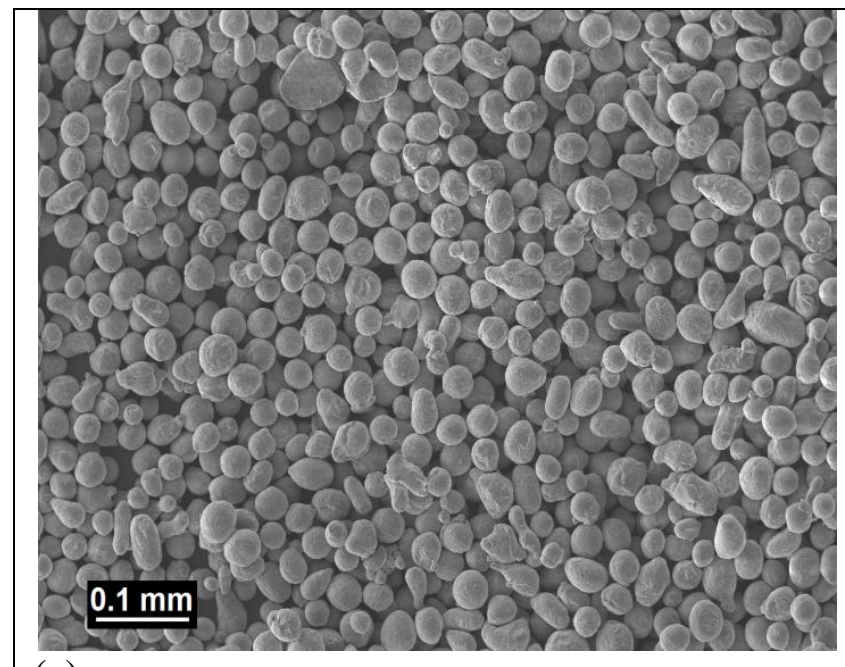

(a)

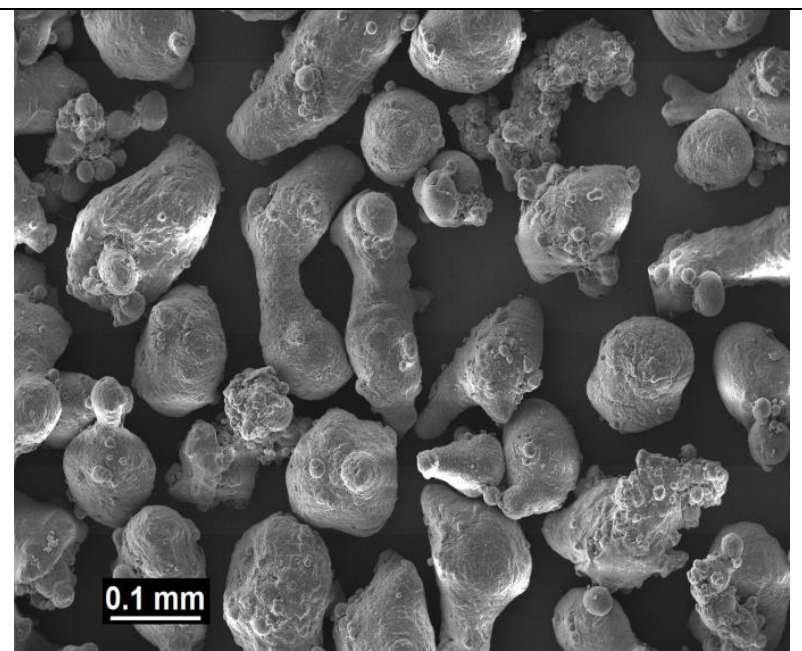

(b)

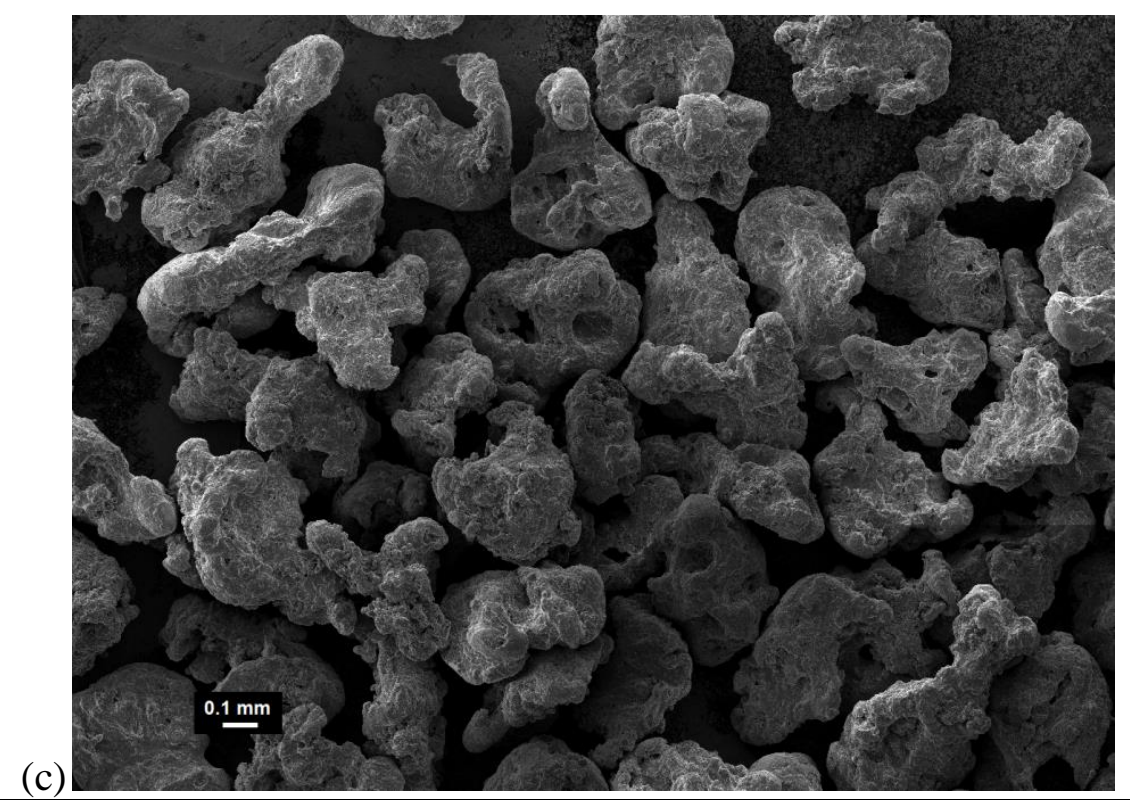

FIG. 1. SEM micrographs of the different Al powder particle sizes: (a) $40 \mu \mathrm{m}$; (b) $100 \mu \mathrm{m}$; (c) $400 \mu \mathrm{m}$. 


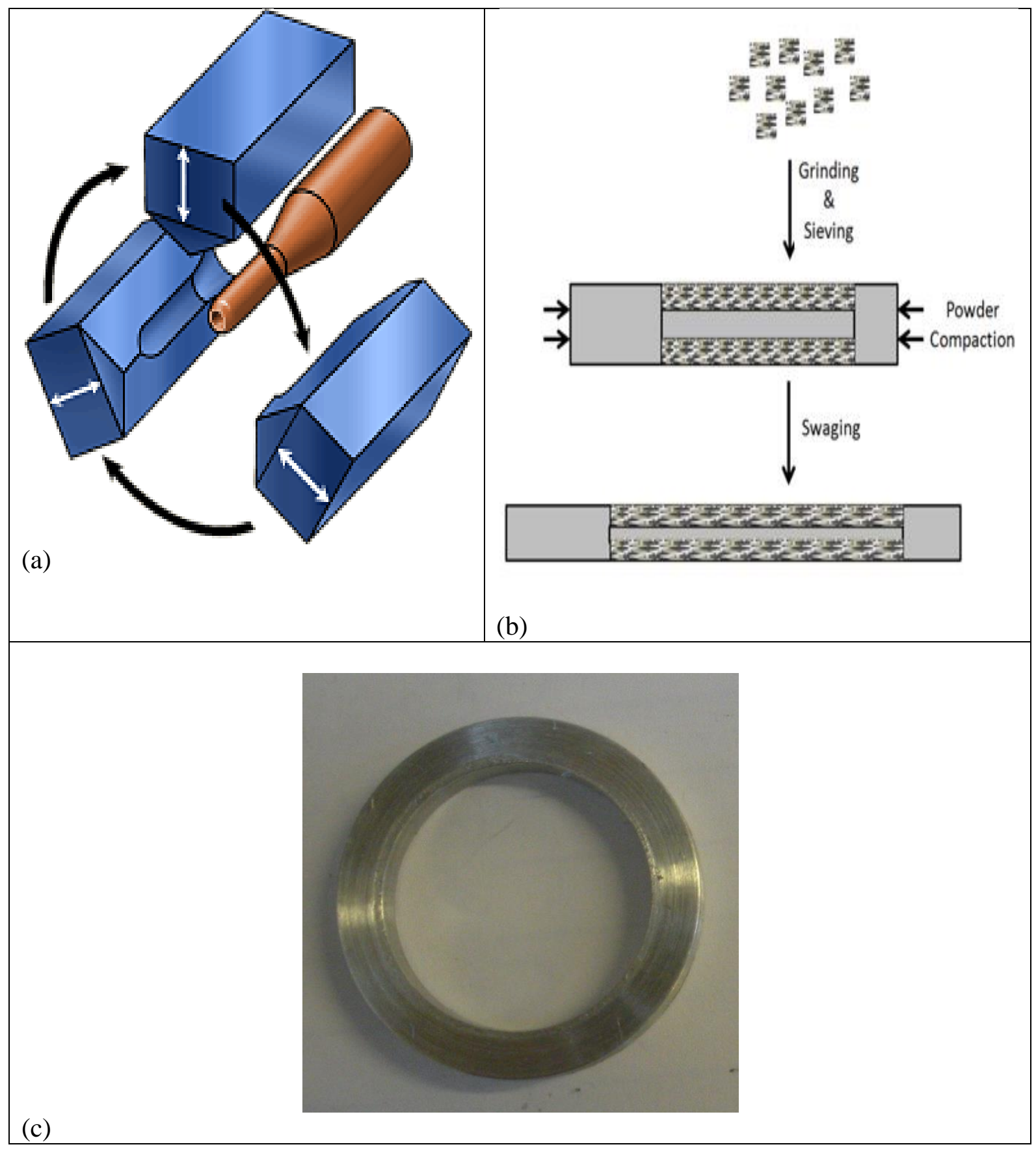

FIG. 2. Diagrams showing: (a) a depiction of the swaging method; (b) the compaction and swaging procedure for powders; and (c) a photograph of a completed swaged aluminum ring. 


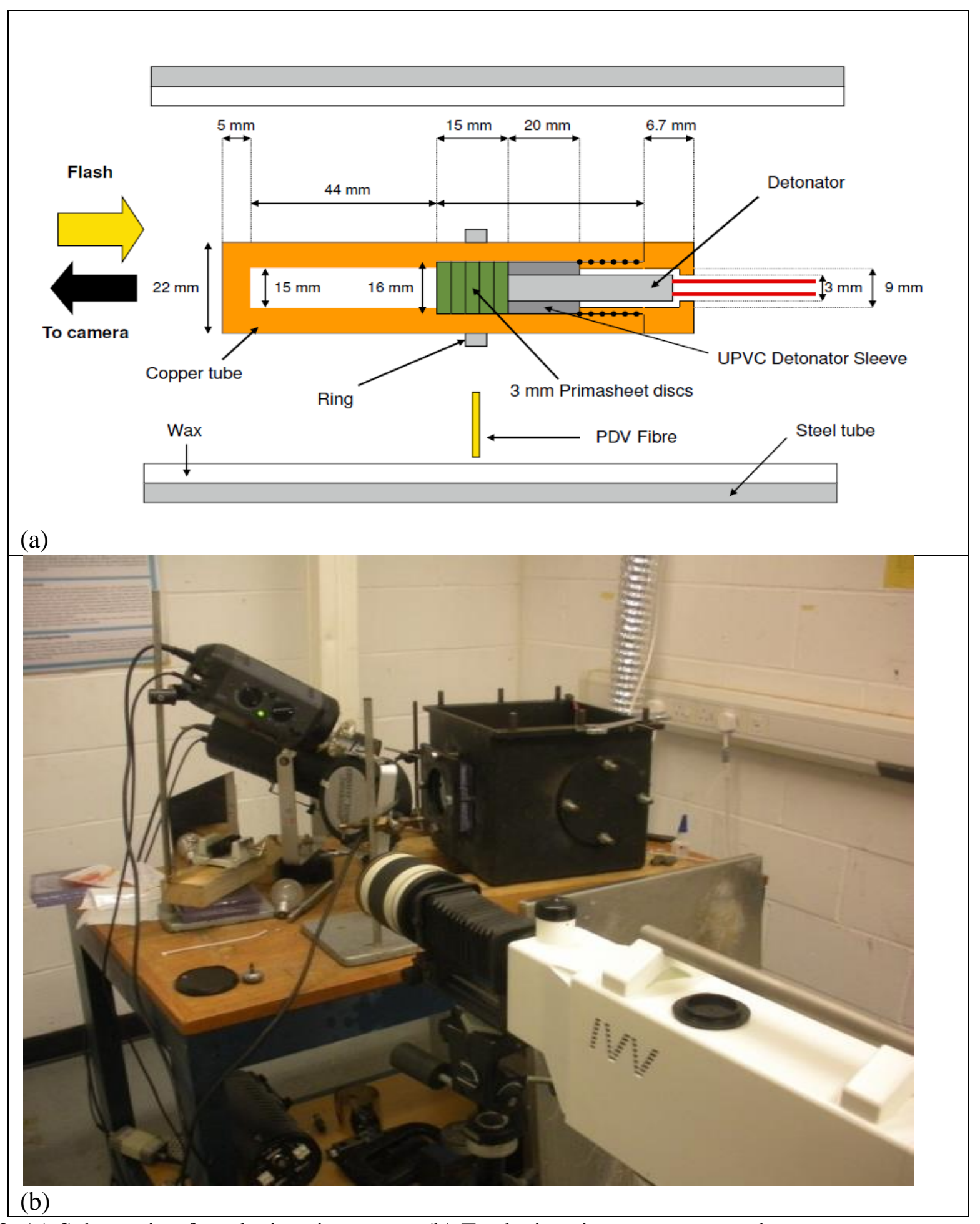

FIG. 3. (a) Schematic of explosive ring setup; (b) Explosive ring apparatus and camera. 


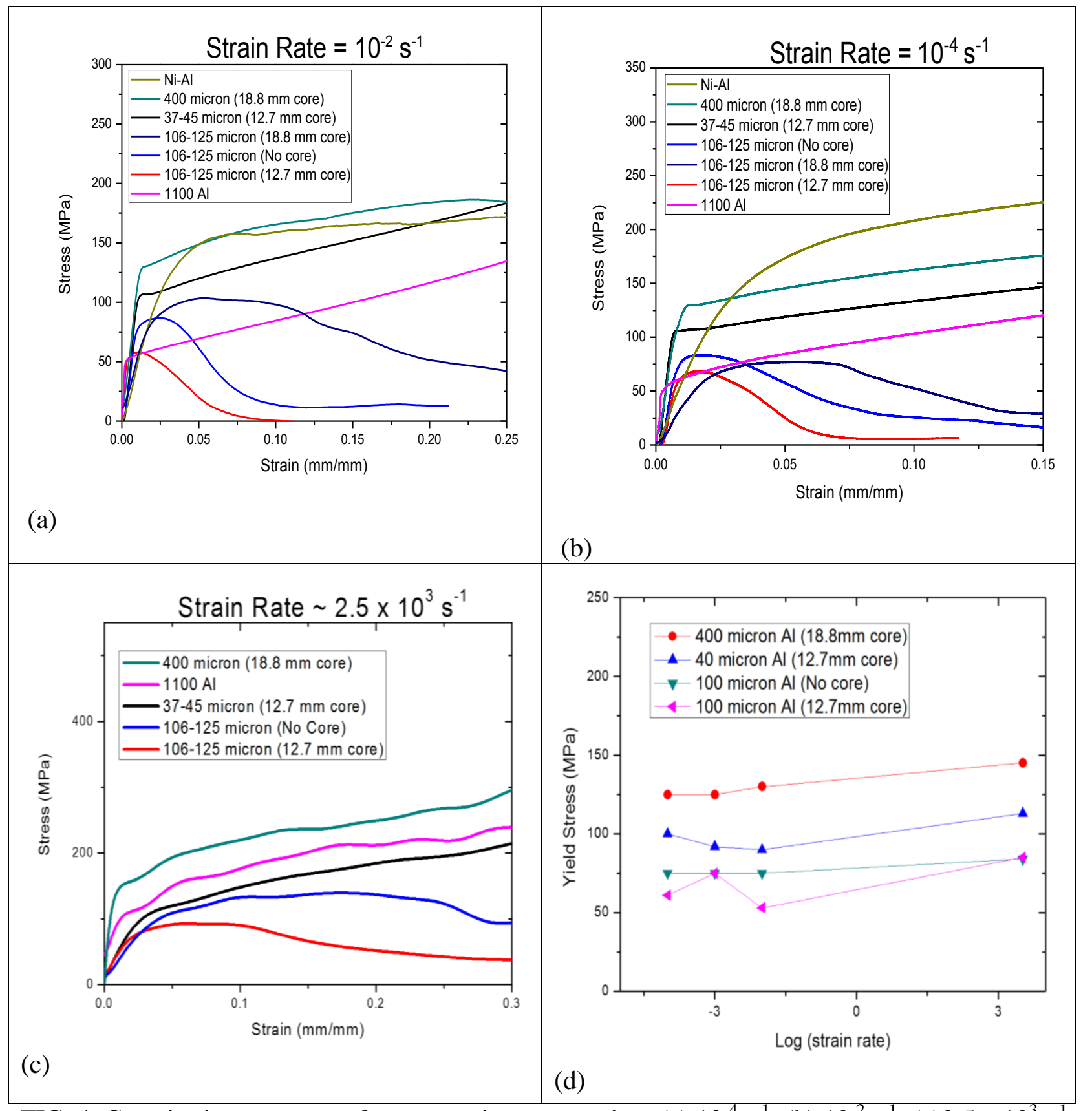

FIG. 4. Constitutive response of compacts in compression: (a) $10^{-4} \mathrm{~s}^{-1}$; (b) $10^{-2} \mathrm{~s}^{-1}$; (c) $2.5 \times 10^{3} \mathrm{~s}^{-1}$; (d) combined plot showing the yield stress as a function of strain rate. 


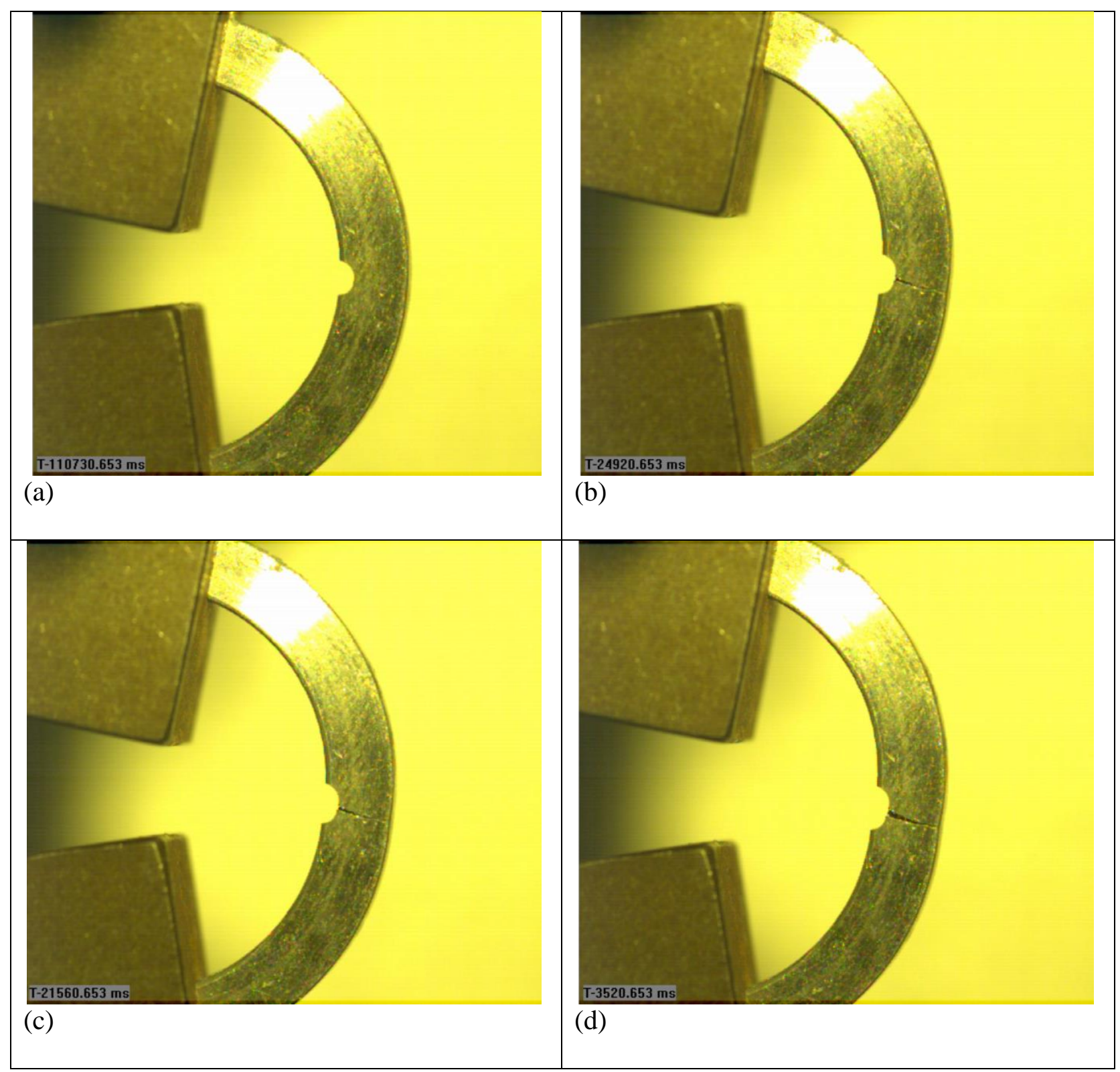

FIG. 5. Several frames from the high-speed recording of the fracture toughness test with the loading fixtures attached at the top and bottom of the specimen: (a) frame captured from the beginning of the test; (b) frame captured at the onset of fracture; (c) frame captured just before complete fracture and failure; (d) frame showing the end of the test. 


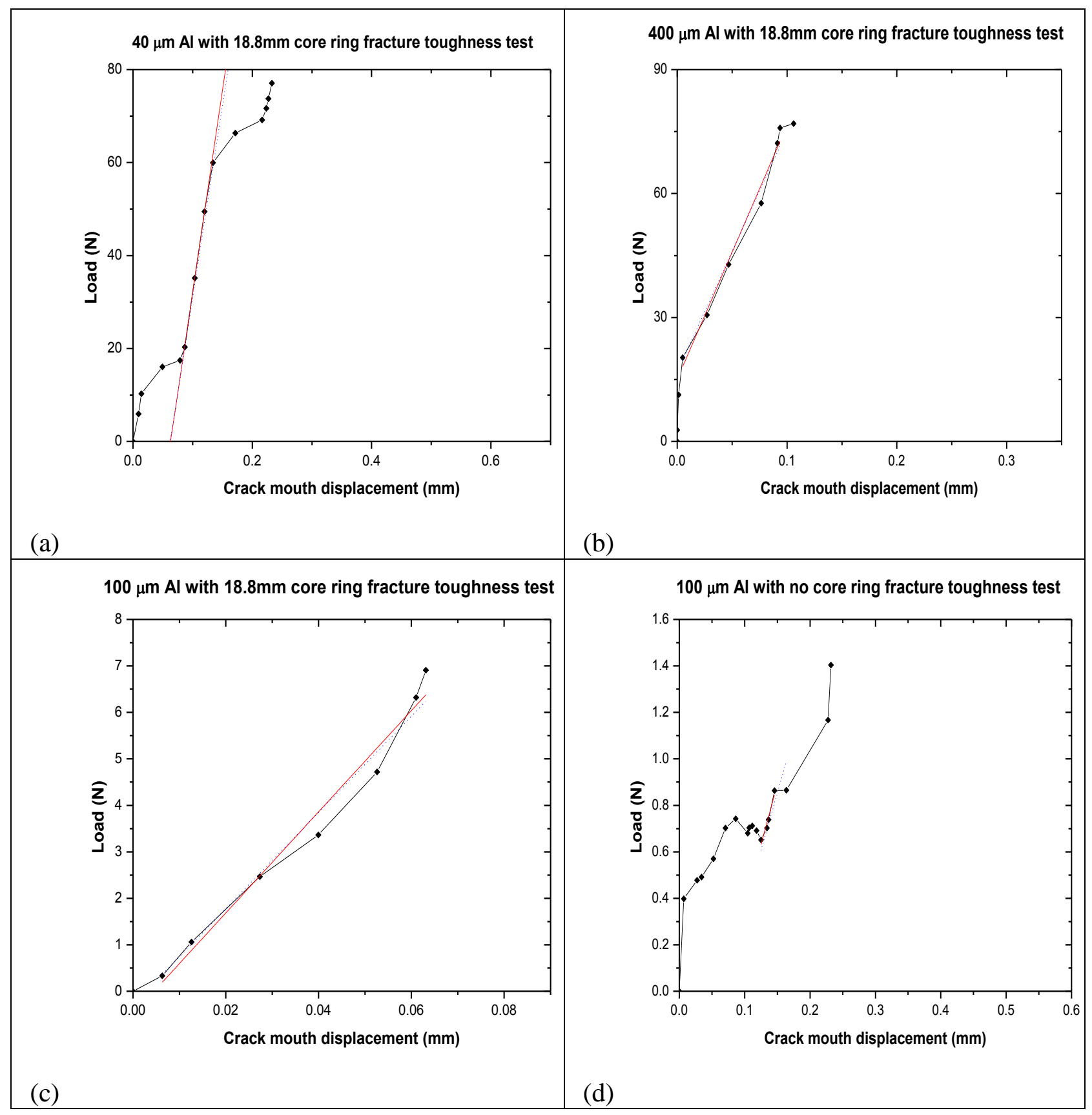

FIG. 6. Force-Crack mouth opening displacement (CMOD) records from the fracture toughness tests with secant lines drawn to obtain the conditional fracture forces of various compacts: (a) 40 $\mu \mathrm{m}$ particle compact; (b) $400 \mu \mathrm{m}$ particle compact; (c) $100 \mu \mathrm{m}$ with $18.8 \mathrm{~mm}$ core compact; (d) $100 \mu \mathrm{m}$ particle with no core compact. 


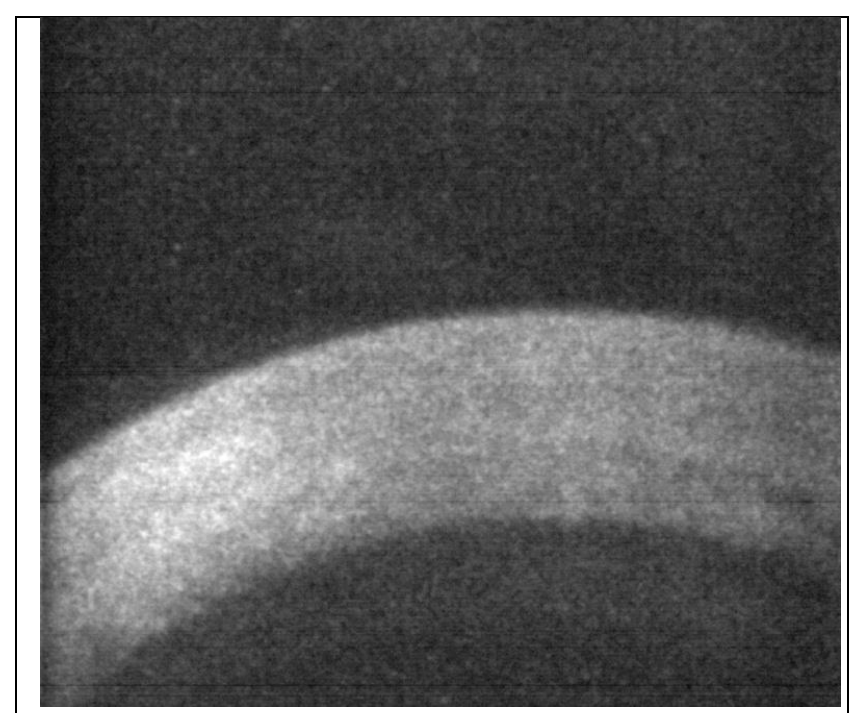

(a)

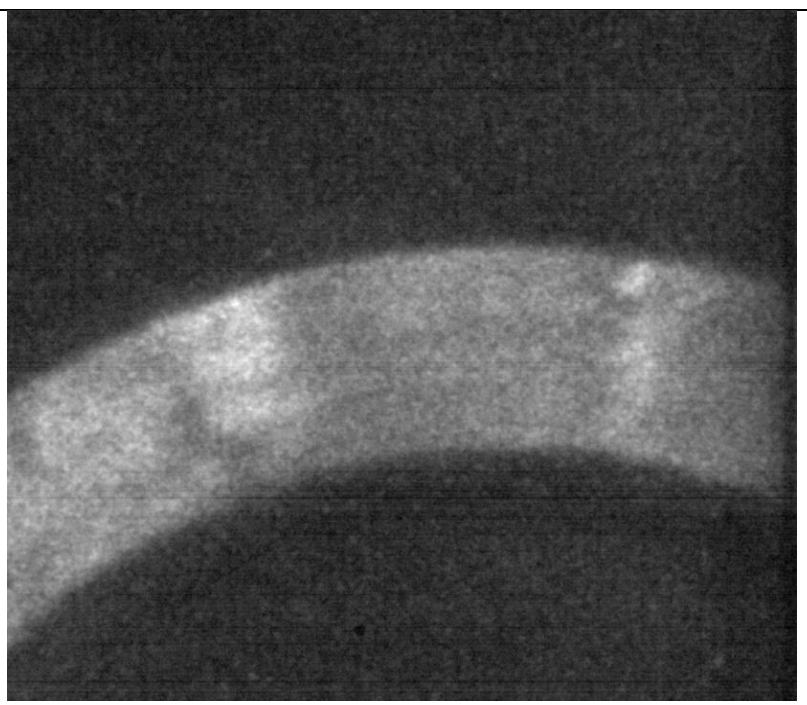

(b)

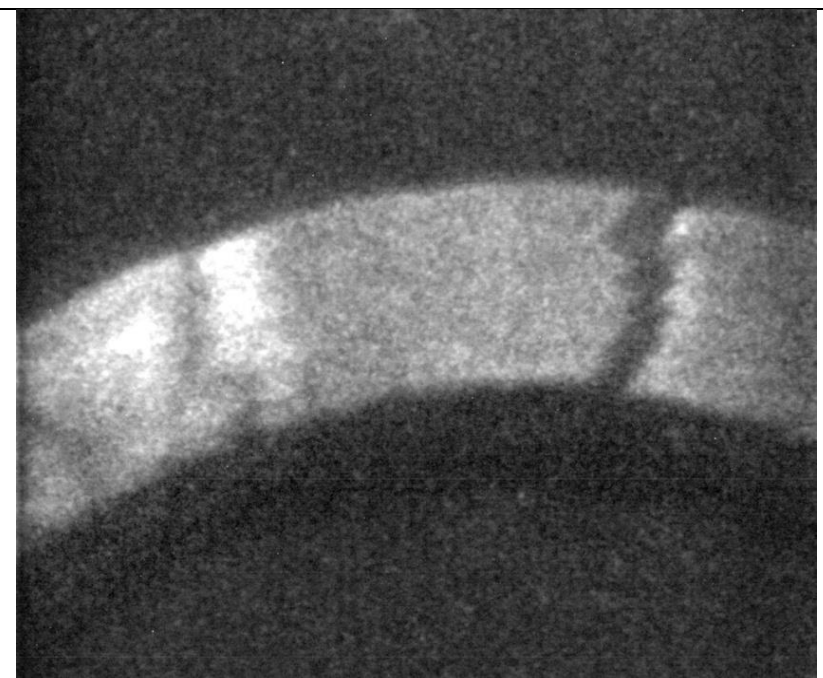

(c)

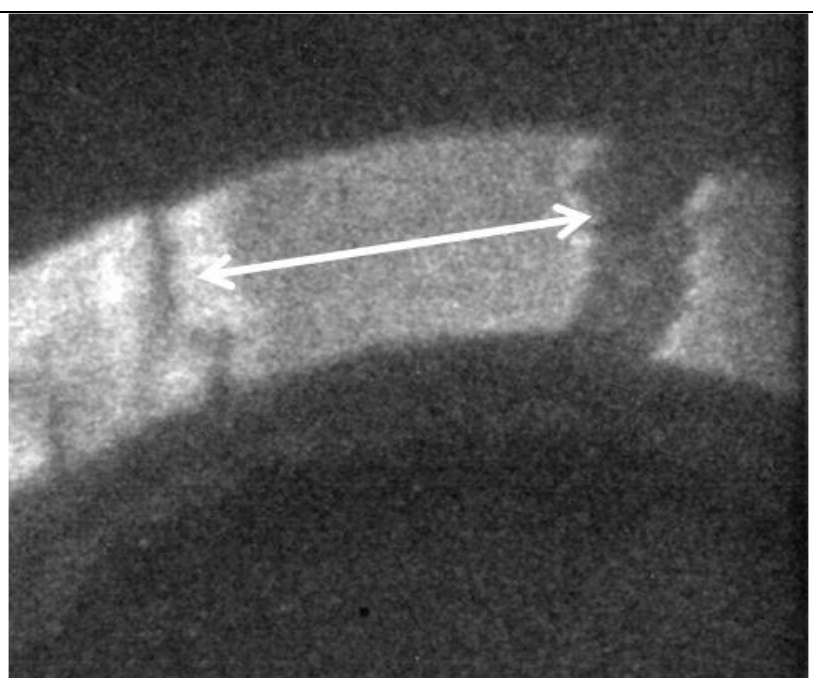

(d)

FIG. 7. Sequence showing initiation of cracking and fragmentation in compact from $40 \mu \mathrm{m}$ powder. Arrow in (d) provides approximate magnitude of fragment length. 


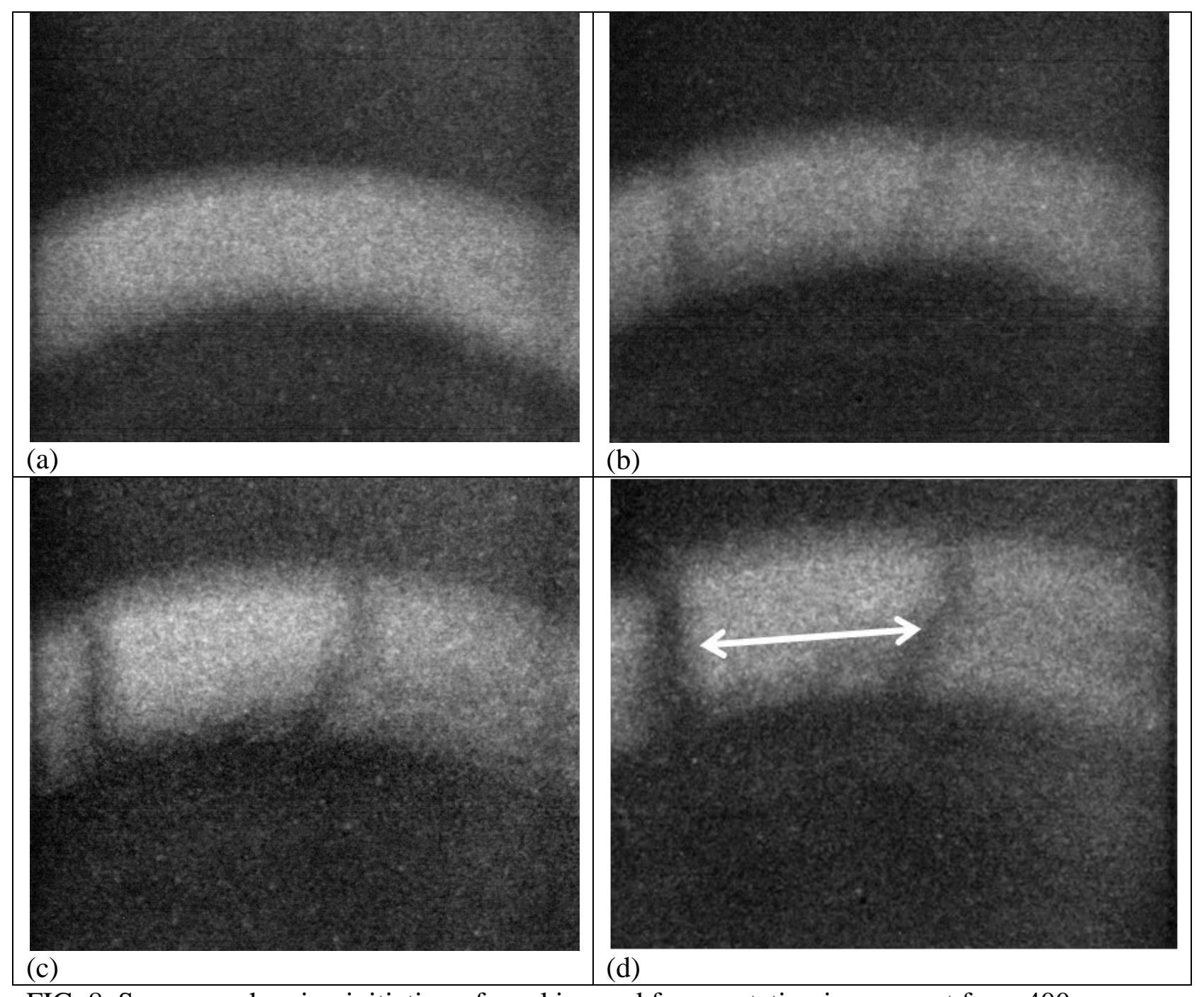

FIG. 8. Sequence showing initiation of cracking and fragmentation in compact from $400 \mu \mathrm{m}$ powder. Arrow in (d) provides approximate magnitude of fragment length. 


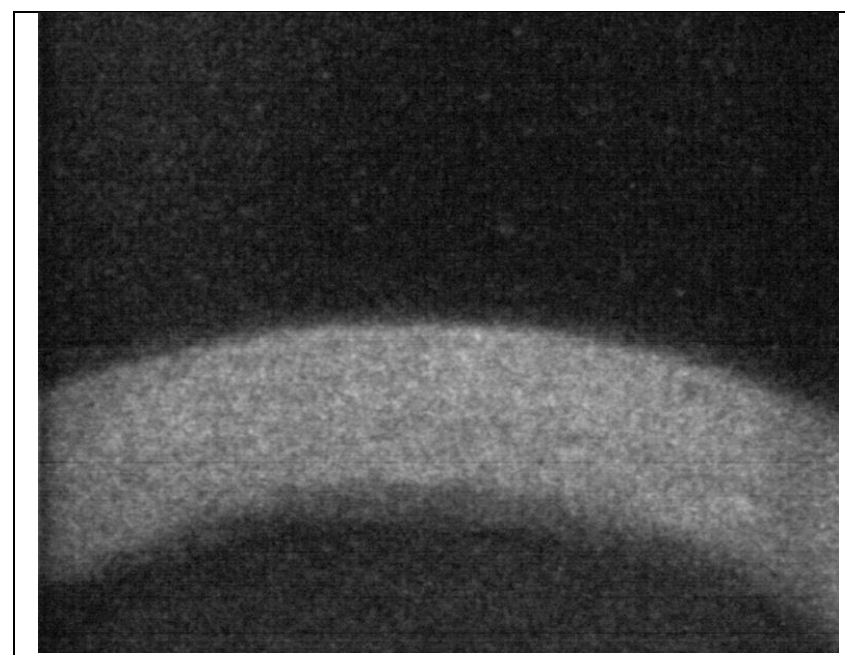

(a)
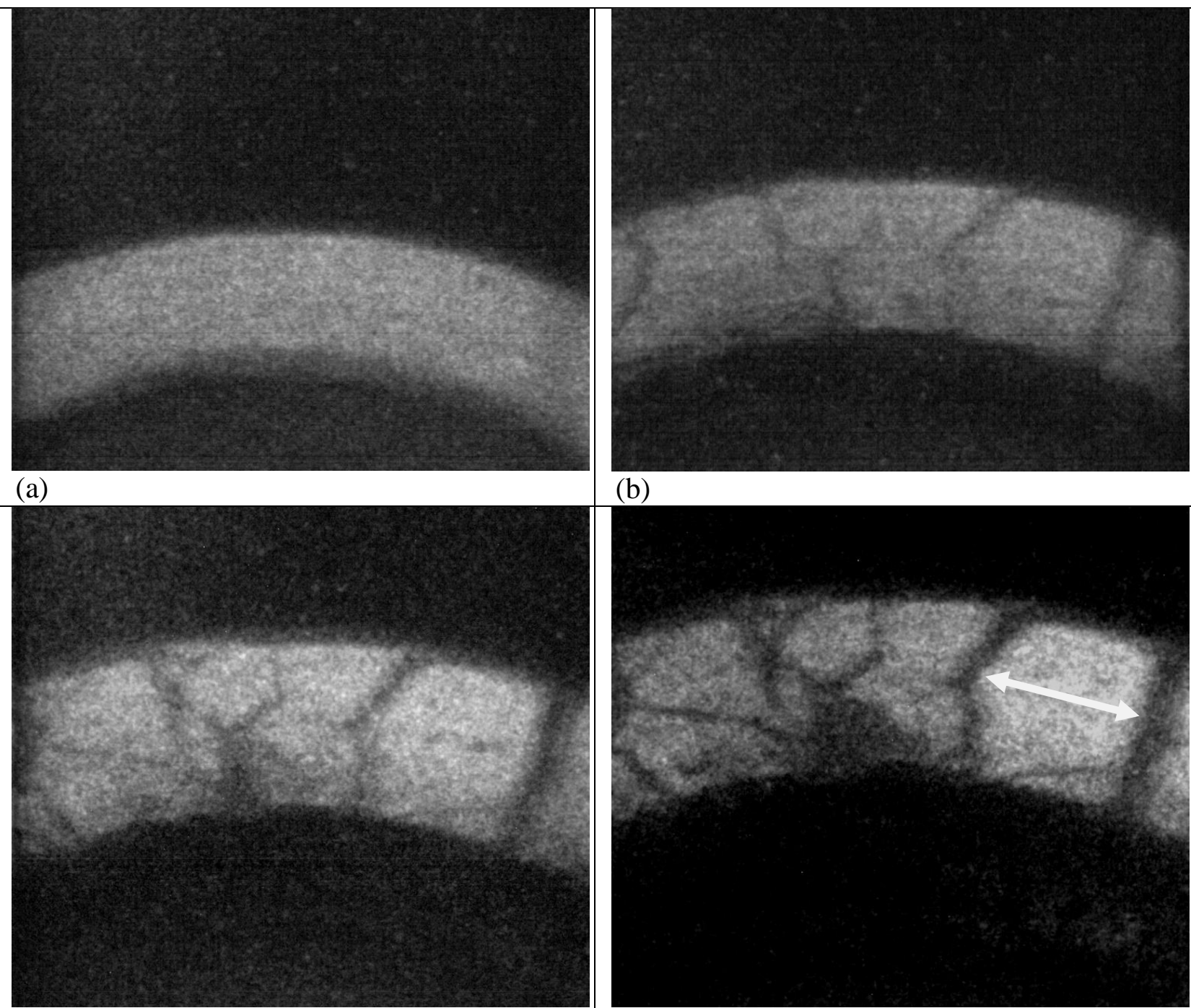

(c)

(b)

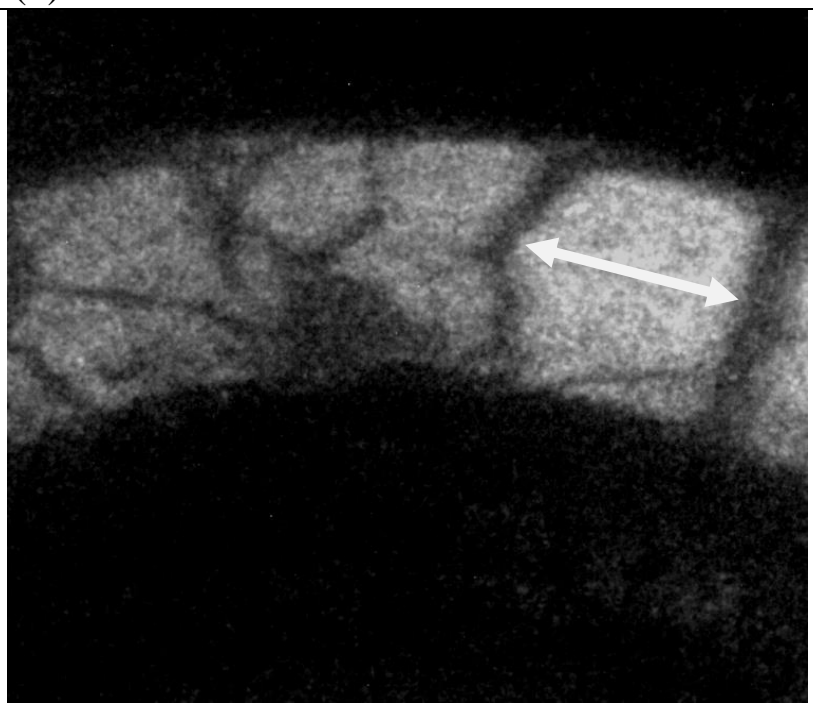

(d)

FIG. 9. Sequence showing initiation of cracking and fragmentation in compact from $100 \mu \mathrm{m}$ powder with a $18.8 \mathrm{~mm}$ core. Arrow in (d) provides approximate magnitude of fragment length. 


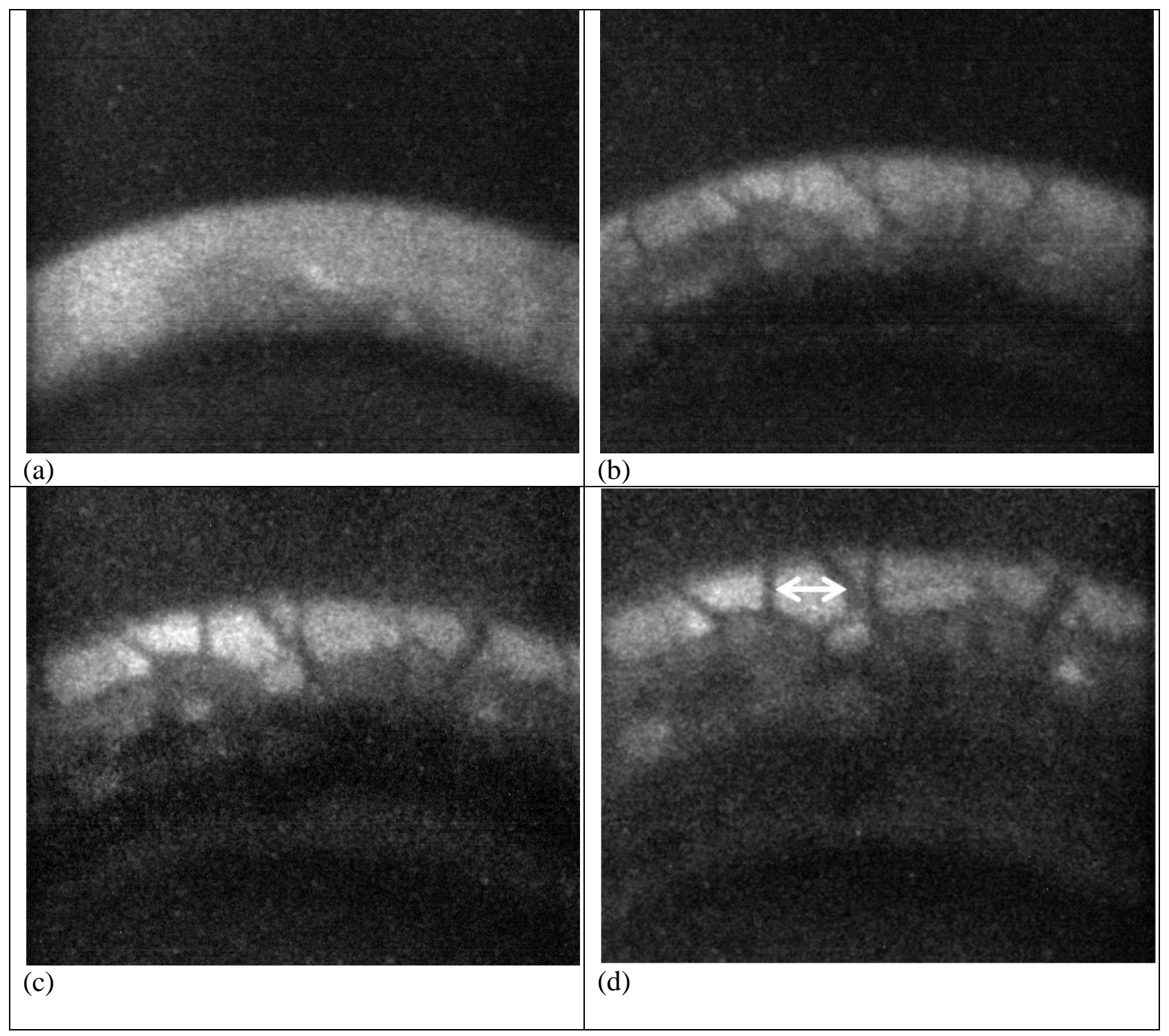

FIG. 10. Sequence showing initiation of cracking and fragmentation in compact from $100 \mu \mathrm{m}$ powder with a $12.7 \mathrm{~mm}$ core. Arrow in (d) provides approximate magnitude of fragment length. 


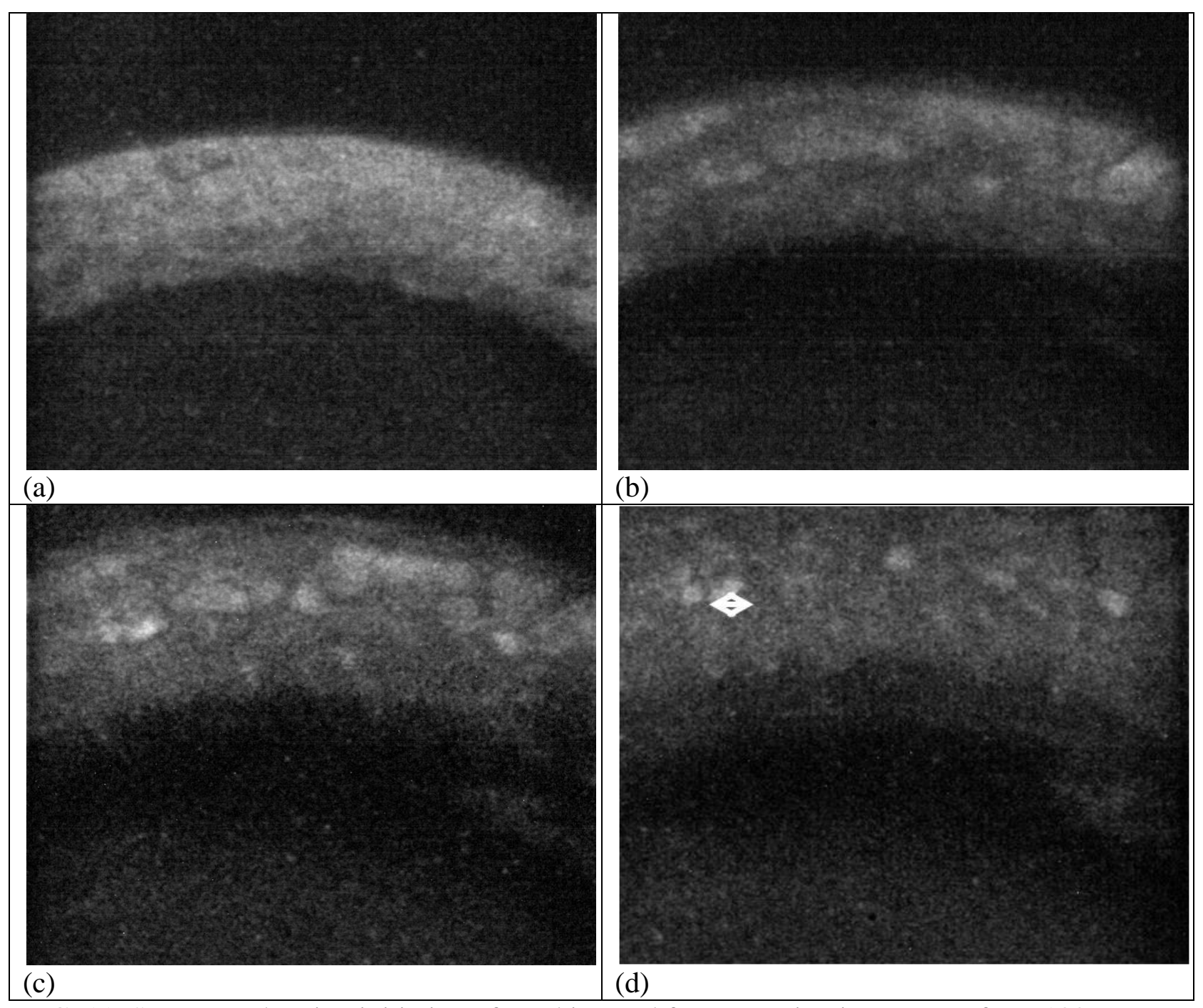

FIG. 11. Sequence showing initiation of cracking and fragmentation in compact from $100 \mu \mathrm{m}$ powder with no core. Arrow in (d) provides approximate magnitude of fragment length. 


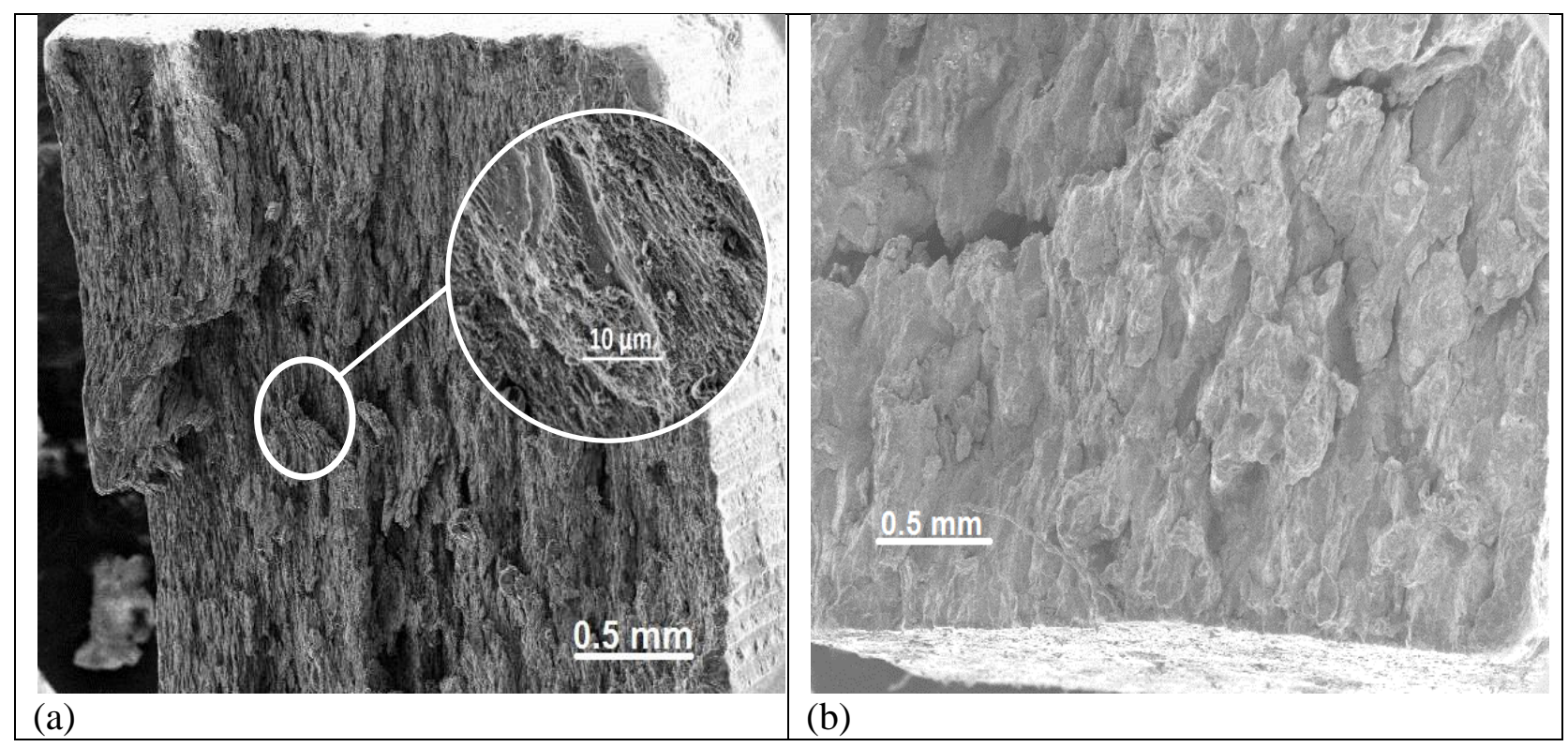

FIG. 12. Fracture surfaces from expanding ring tests: (a) compact from $40 \mu \mathrm{m}$ powder; (b) compact from $400 \mu \mathrm{m}$ powder. Note the rolling uneven surfaces in both fractures that are indicative of ductile deformation and at a high magnification in the $40 \mu \mathrm{m}$ fracture surface, shown by the inset image, there is visible elongated dimple morphology. 


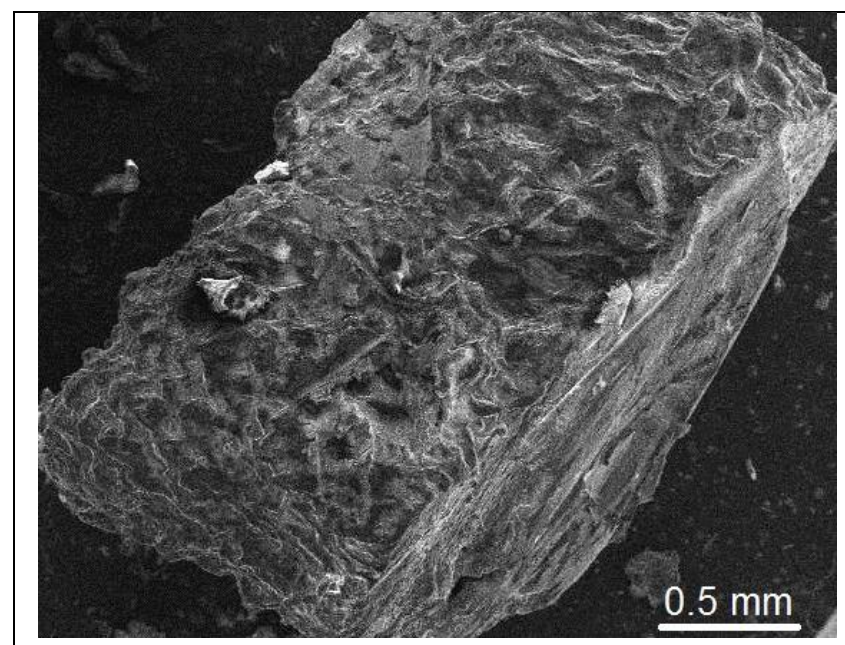

(a)

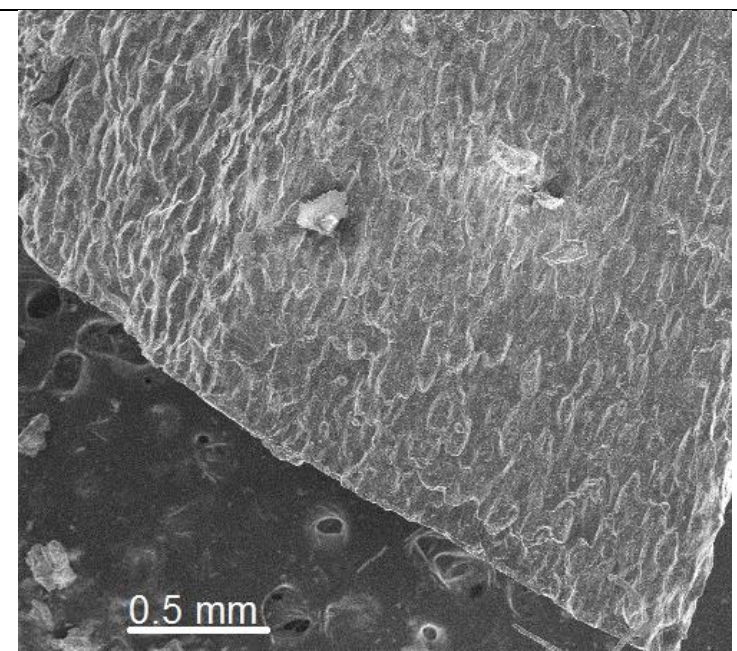

(b)

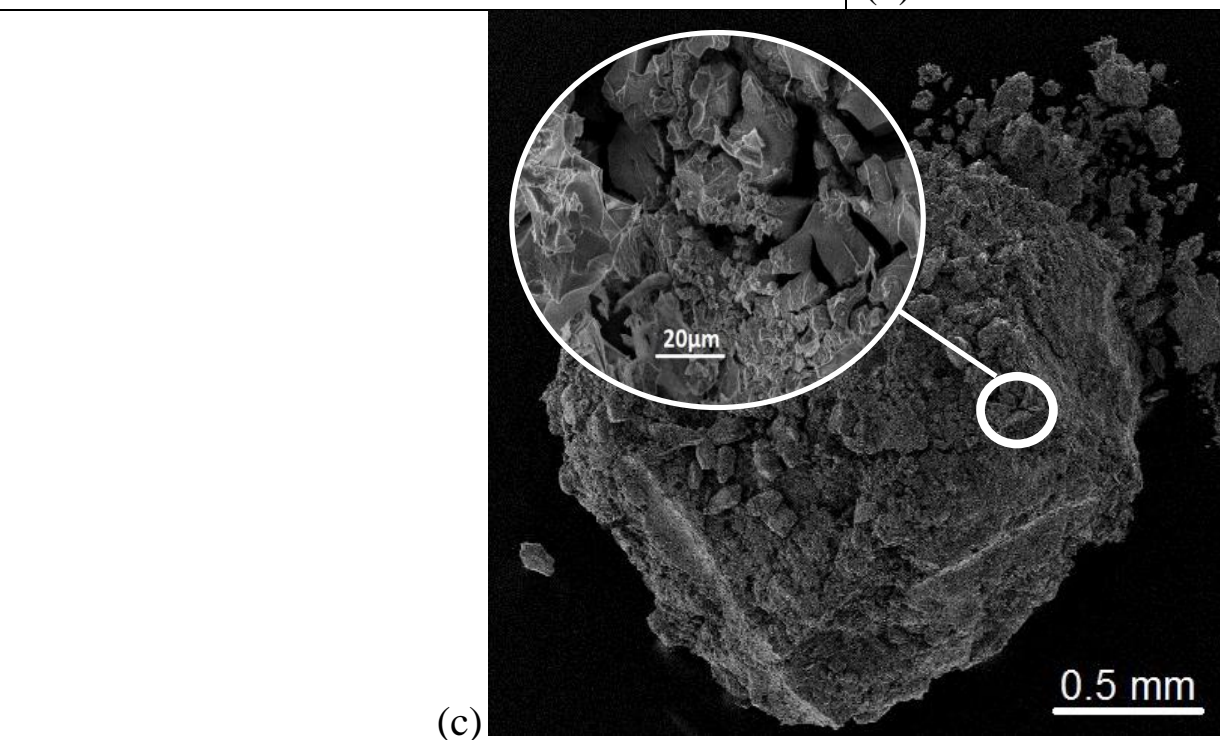

FIG. 13. Fracture surfaces from expanding ring tests of compacts made from $100 \mu \mathrm{m}$ powder: (a) $18.8 \mathrm{~mm}$; (b) $12.7 \mathrm{~mm}$; (c) no core. Note the interfacial cracking on these surfaces that are indicative of brittle failure, specifically in the high magnification inset of the fragment from the compact swaged with no core. 


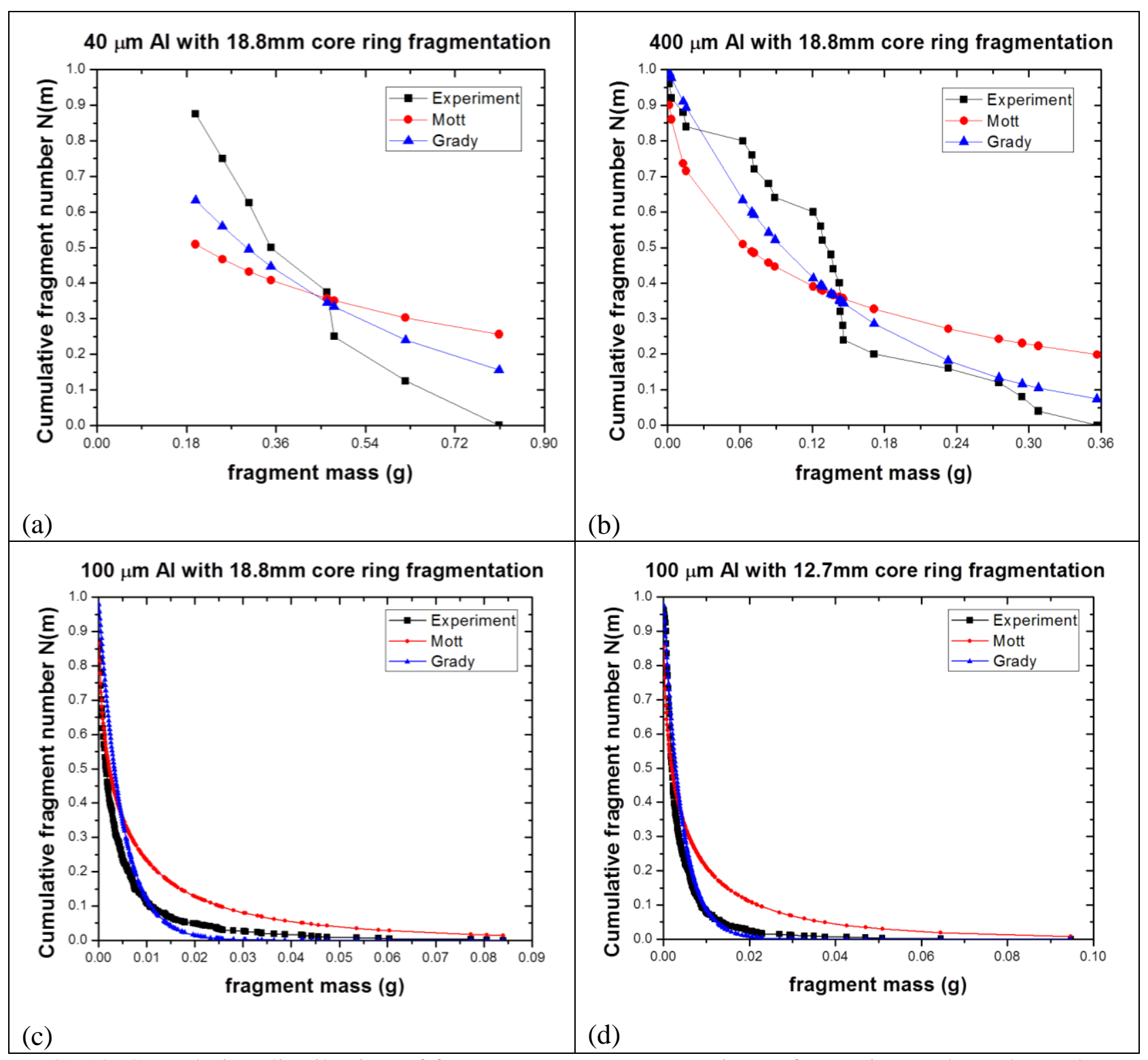

FIG. 14. Cumulative distribution of fragment masses: comparison of experimental results and theories by Mott and Grady: (a) $40 \mu \mathrm{m}$ particle compact; (b) $400 \mu \mathrm{m}$ particle compact; (c) 100 $\mu \mathrm{m}$ with $18.8 \mathrm{~mm}$ core compact; (d) $100 \mu \mathrm{m}$ particle with $12.7 \mathrm{~mm}$ core compact. 
(a)
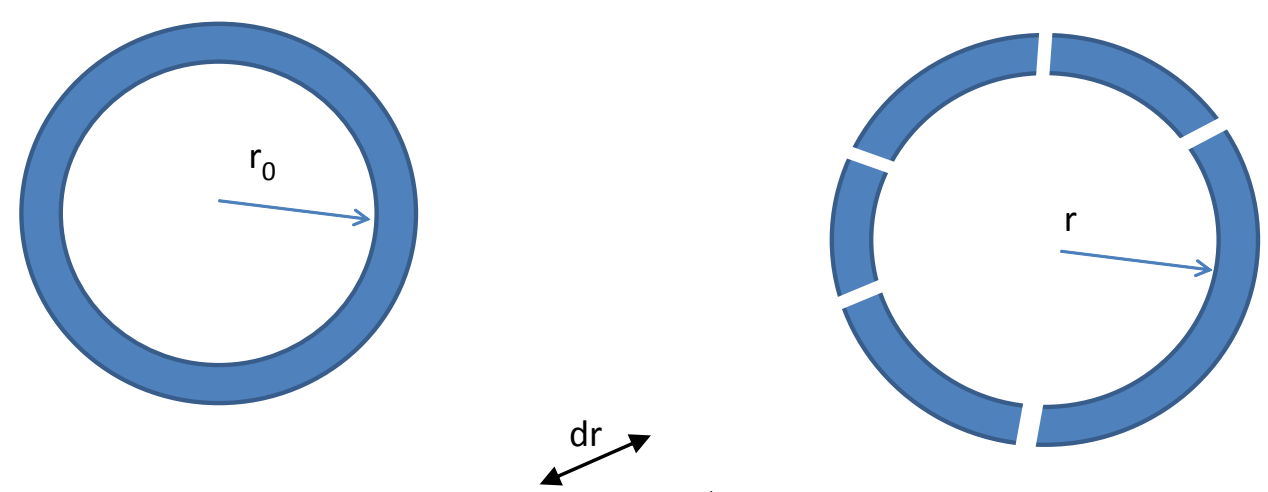

(b)
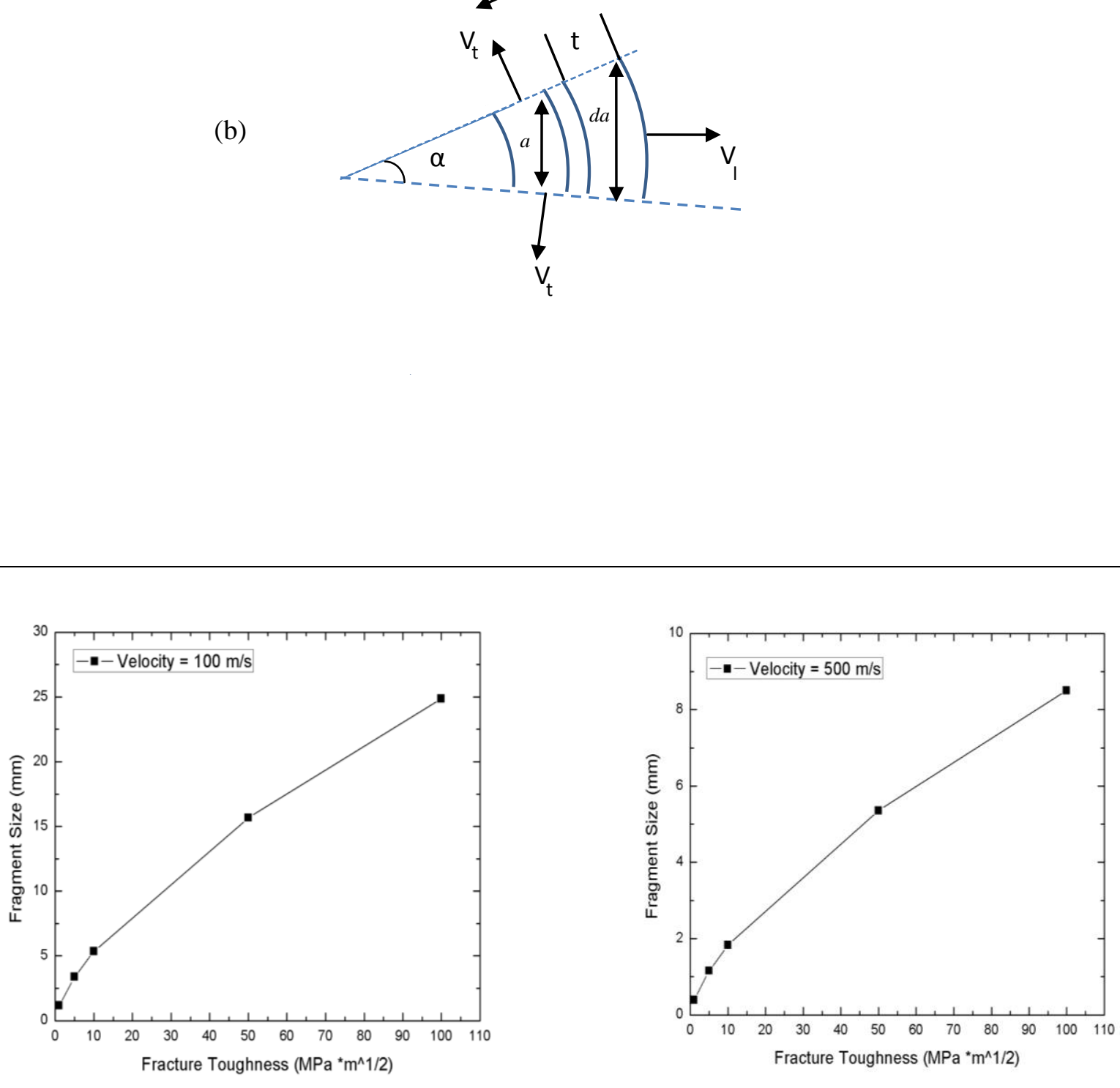

(c)

FIG. 15. Analysis of fragmentation following Mott: (a) fragmentation of ring into segments; (b) segment of ring with parameters used in derivation; (c) predictions of Mott and modified Mott theory: fragment size as a function of fracture toughness for aluminum at two velocities: $V_{l}=100$ and $500 \mathrm{~m} / \mathrm{s}$. 


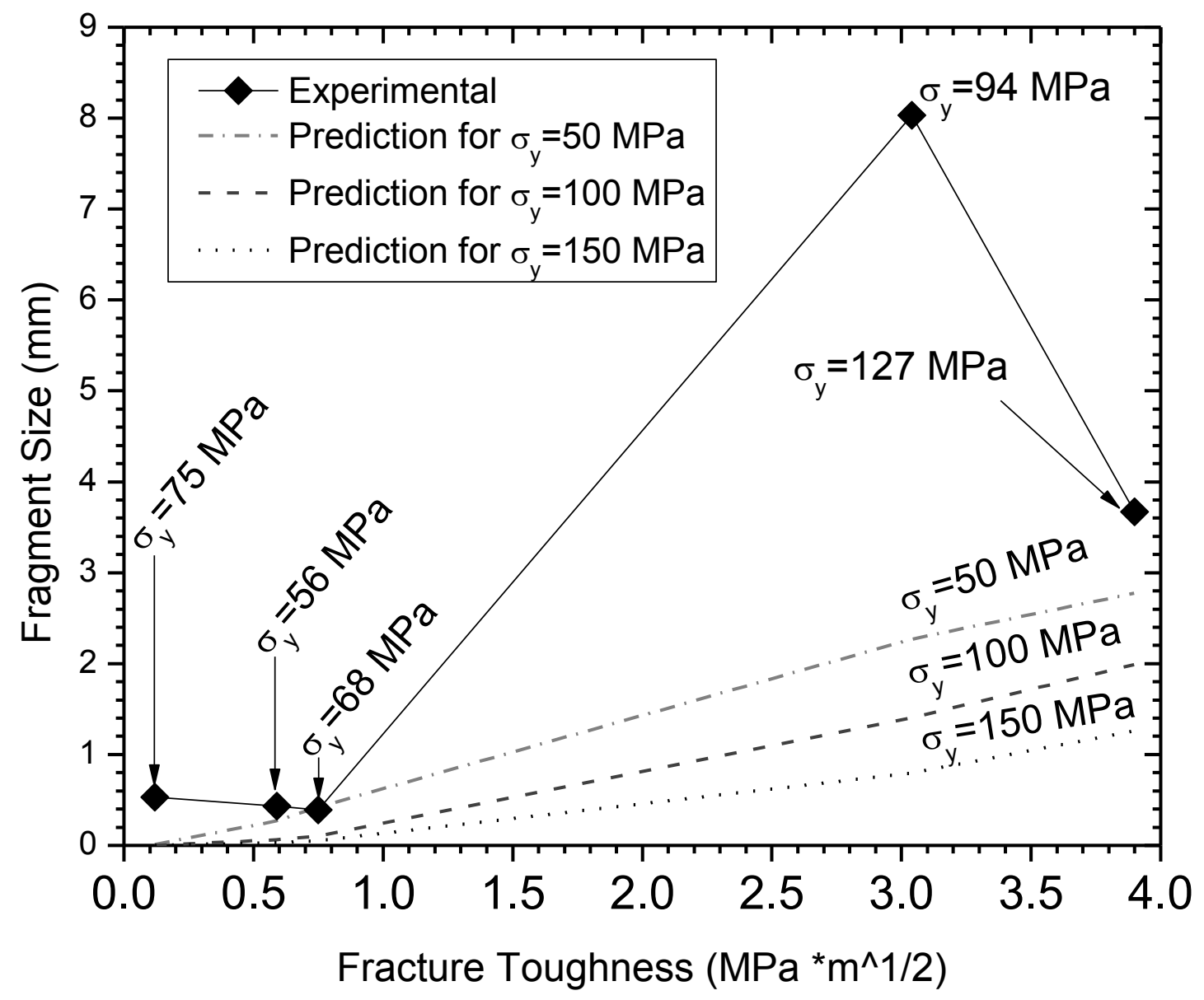

FIG. 16. Experimentally measured mean fragment sizes (solid lines) of the swaged aluminum compared to the predictions for fragment sizes based on fracture toughness with the modified Mott theory within a range of yield stresses typical to the swaged aluminum (dotted, dash dotted, and dashed lines). The fragment size is dependent on yield stress, as shown by the three curves for 50, 100 and $150 \mathrm{MPa}$. The yield stresses of the experimental conditions are noted above each point. 


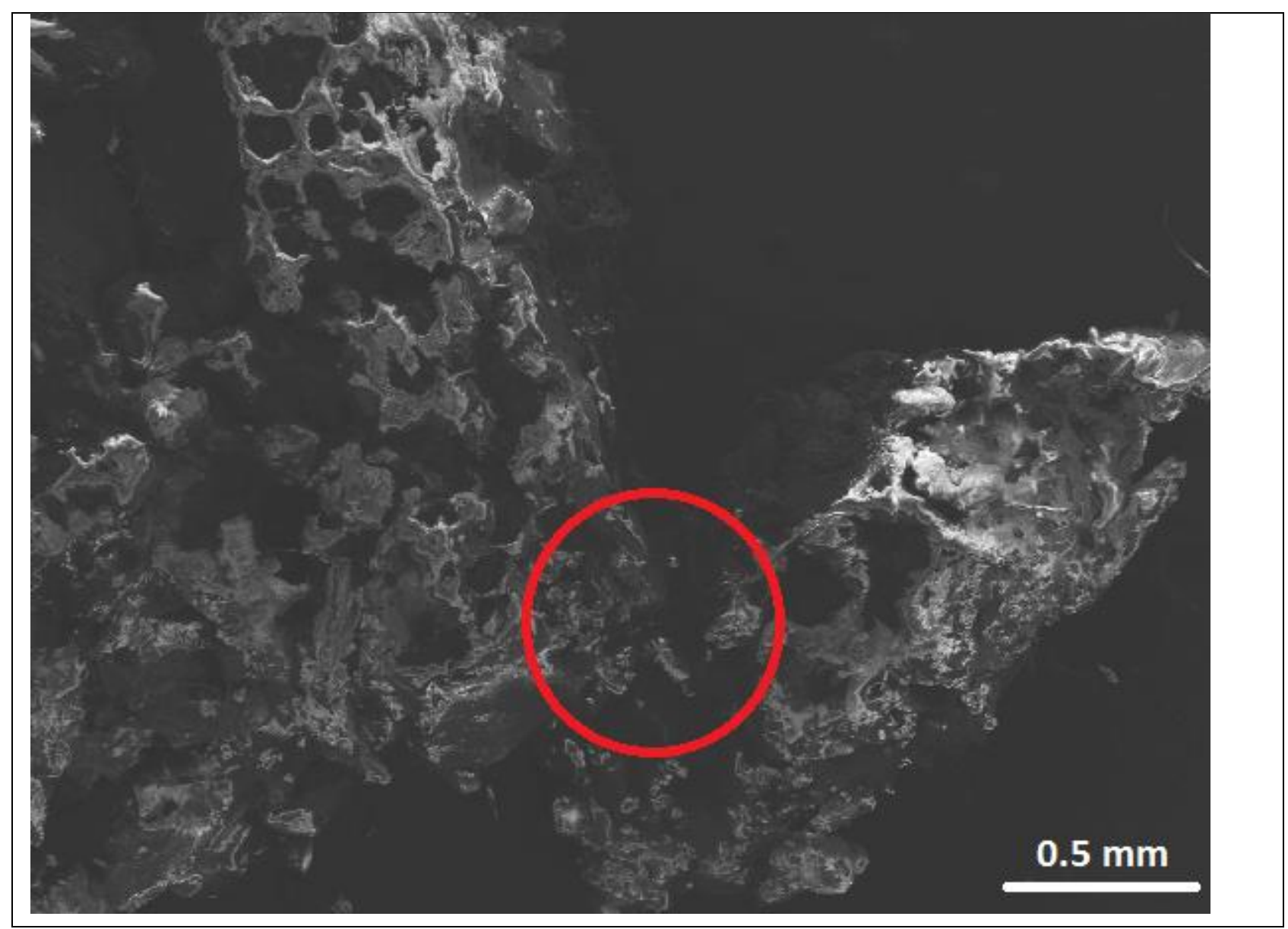

FIG. 17. Scanning electron micrograph of fragments from the 100 micron aluminum ring, swaged with no core, compacted together at the edges as highlighted in the outlined area after an expanding ring test. The high contrast is due to the charge in the fragments being altered by wax also compacted with the fragments in the test. 